\title{
The role of the microbiome in ovarian cancer: mechanistic insights into oncobiosis and to bacterial metabolite signaling
}

Adrienn Sipos ${ }^{1}$, Gyula Ujlaki ${ }^{1}$, Edit Mikó', Eszter Maka², Judit Szabó ${ }^{3}$ Karen Uray ${ }^{1}$, Zoárd Krasznai and Péter Bai ${ }^{1,4,5^{*}}$ (1)

\begin{abstract}
Ovarian cancer is characterized by dysbiosis, referred to as oncobiosis in neoplastic diseases. In ovarian cancer, oncobiosis was identified in numerous compartments, including the tumor tissue itself, the upper and lower female genital tract, serum, peritoneum, and the intestines. Colonization was linked to Gram-negative bacteria with high inflammatory potential. Local inflammation probably participates in the initiation and continuation of carcinogenesis. Furthermore, local bacterial colonies in the peritoneum may facilitate metastasis formation in ovarian cancer. Vaginal infections (e.g. Neisseria gonorrhoeae or Chlamydia trachomatis) increase the risk of developing ovarian cancer. Bacterial metabolites, produced by the healthy eubiome or the oncobiome, may exert autocrine, paracrine, and hormonelike effects, as was evidenced in breast cancer or pancreas adenocarcinoma. We discuss the possible involvement of lipopolysaccharides, lysophosphatides and tryptophan metabolites, as well as, short-chain fatty acids, secondary bile acids and polyamines in the carcinogenesis of ovarian cancer. We discuss the applicability of nutrients, antibiotics, and probiotics to harness the microbiome and support ovarian cancer therapy. The oncobiome and the most likely bacterial metabolites play vital roles in mediating the effectiveness of chemotherapy. Finally, we discuss the potential of oncobiotic changes as biomarkers for the diagnosis of ovarian cancer and microbial metabolites as possible adjuvant agents in therapy.
\end{abstract}

Keywords: Ovarian cancer, Microbiome, EMT, Microbial metabolite, Indole derivative, Lipopolysaccharide, Lysophosphatid, Antibiotic, Probiotic

\section{Background}

Ovarian cancer is leading oncological cause of death among women. Ovarian cancer is characterized by changes to different microbiome compartments that is termed oncobiosis. The aim of the current work is to provide a comprehensive review of changes to microbiome and to give mechanistic insights to the role of the microbiome in the pathogenesis of ovarian cancer. These

*Correspondence: baip@med.unideb.hu

${ }^{1}$ Department of Medical Chemistry, Faculty of Medicine, University of Debrecen, Debrecen 4032, Hungary

Full list of author information is available at the end of the article mechanistic steps involve, but are not limited to the induction of sustained inflammation and the production of procarcinogenic bacterial metabolites. The interference between the oncobiome and the chemotherapeutic agents will be discussed, as well as, the possible application of antibiotics, probiotics and nutrients in the management of ovarian cancer.

\section{Etiology and treatment of ovarian cancer}

Ovarian cancer is the second most common gynecological malignancy in developed countries and has one of the worst prognosis and mortality (Torre et al. 2015). Most ovarian tumors, approximately $90 \%$, are of epithelial 
origin (Heintz et al. 2001; Banks 2001). According to the presently accepted dualistic model, ovarian cancer is not a single homogenous disease, but consists of two major types, type I and II (Kurman 2013). Type I tumors (30\%) are low-grade tumors, which are clinically slow-growing large cystic formations with mutations in KRAS, BRAF, PTEN, CTNNB1, PIK3CA, PPP2R1A, and ARID1A genes (Shih Ie and Kurman 2004; Wiegand et al. 2010). On the contrary, type II tumors, accounting for $70 \%$ of all ovarian malignancies, are aggressive high-grade cancers that almost always present as advanced stage with high fatality. Type II tumors have alterations in the TP53, BRCA1, BRCA2 genes and have very high genetic instability (Kurman 2013; Kurman and Shih 2011). Approximately $90 \%$ of type II tumors are high-grade serous cancers (HGSC) and are derived from serous tubal interstitial carcinoma (STIC) of the fallopian tube (Kurman 2013; Carlson et al. 2008; Kindelberger et al. 2007). Hereditary factors are responsible for about $20 \%$ of all ovarian cancers, stemming from mostly BRCA1 and BRCA2 mutations (Lynch et al. 1993; Risch et al. 2006; Medeiros et al. 2006). Somatic alterations of genes in the homologous repair pathways are more frequent than those of germ-line origin. More than $2 / 3$ of patients present with advanced-stage (FIGO III-IV) disease.

A complete tumor reduction, called primary debulking surgery, is the cornerstone of initial treatment for ovarian cancer. Tumor reduction may necessitate multiple organ resections (bowel resection, peritonectomy, and splenectomy) (Chang et al. 2012; Querleu et al. 2017). The goal is to achieve "optimal" cytoreduction, which is defined as "no residual macroscopic disease", according to the Vancouver Consensus Conference 2010 (Stuart et al. 2011). If optimal tumor reduction is not feasible, neoadjuvant intravenous chemotherapy with paclitaxel and carboplatin is initiated and an interval debulking surgery (IDS) is performed, if a partial or complete response is observed after 3 cycles (Querleu et al. 2017; Vergote et al.2010; Zeng et al.2016; Fagotti et al. 2016). Since neoadjuvant chemotherapy increases the rate of complete tumor reduction, but does not improve survival, it is only non-inferior to upfront surgery, which is preferred if possible (Morrison et al. 2012; Medina-Franco et al. 2017). In cases of HGSC, surgery is followed by adjuvant chemotherapy.

The standard of care for the past 20 years is a combination of paclitaxel and platinum, which is routinely administered intravenously (Jayson et al. 2014). This therapy is superior, as the first-line treatment of ovarian cancer, over any other drug combination (Kyrgiou et al. 2006). The modified dose-dense treatment with weekly paclitaxel regimen further improves survival, although side effects are more severe (Katsumata et al. 2009). Although intraperitoneal chemotherapy seems to have survival benefits over intravenous administration according to some trials, intraperitoneal treatment has a higher complication rate (e.g. catheter-related problems) and is not routinely used, although the option is open for select cases (Jaaback and Johnson 2006).

Angiogenesis plays a very important role in the peritoneal spread and metastasis forming potential of ovarian cancer (Yoneda et al. 1998). Therefore, targeted therapies against vascular endothelial growth factor (VEGF) have important therapeutic effects (Burger et al. 2011). If tumor reduction is not complete during surgery, patients receive bevacizumab, an anti-VEGF monoclonal antibody (NCCN Guidelines). Bevacizumab prolongs progressionfree survival and quality of life. However, bevacizumab is beneficial for overall survival only in poor prognosis groups (Stark et al. 2013; Tewari et al. 2019).

Poly[ADP-ribose] polymerase (PARP) plays an essential role in DNA repair (Curtin and Szabo 2013). Patients with germline or somatic BRCA1/2 mutations who show partial or complete response to platinum chemotherapy receive PARP inhibitors (olaparib or niraparib) as a maintenance therapy (NCCN Guidelines) [for an overview on the current studies see (Curtin et al. 2020; Mateo et al. 2019; Curtin and Szabo 2020)]. Even patients without known BRCA 1/2 mutations may benefit from maintenance niraparib therapy after first-line treatment, because other homologous repair defects may be present in the tumor (NCCN Guidelines). If bevacizumab is part of the primary therapy, the addition of olaparib in combination with maintenance therapy gives a significant progression-free survival benefit to patients regardless of BRCA1/2 mutation status (Ray-Coquard et al. 2019).

Despite initial therapy, the disease recurs in about $70-80 \%$ of advanced-stage patients, and the 10 year disease-free survival rate is below $15 \%$ in these patients (Coleman et al. 2019; Dood et al. 2018). If the disease recurs 12 months or later after the end of platinum therapy, the tumor is "platinum sensitive", in a range between 6 and 12 months the tumor is "partially platinum sensitive", and recurrence within 6 months means "platinum resistant" disease. Patients with platinum sensitive recurrence receive platinum reinduction therapy with paclitaxel and carboplatin, while the management of platinum-resistant disease is a much greater challenge. In the latter cases, single agent paclitaxel, topotecan, and pegylated liposomal doxorubicin (PLD) remain an option (Bergamini et al. 2019). These drugs can also be given in combination with bevacizumab as second-line therapy (Poveda et al. 2015). In addition, PARP inhibitors have an important role in the management of recurrent disease (NCCN Guidelines; Ledermann et al. 2012; Mirza et al. 2016). There is strong evidence that secondary 
cytoreductive surgery does not improve survival of recurrent ovarian cancer patients (Coleman et al. 2019).

\section{Interactions between the oncobiome and cancer}

A large set of neoplastic diseases are characterized by changes to microbiome compartment(s) that is termed oncobiosis, the opposite of which is eubiosis. Oncobiosis has a role in the pathogenesis of neoplastic diseases. Microbiome-neoplastic cell interactions are multipronged (Miko et al. 2016; Miko et al. 2019; Zitvogel et al. 2017; Kovacs et al. 2020; Finlay et al. 2020) and can impact on multiple cancer hallmarks (for cancer hallmarks, see the seminal papers of Hanahan and Weinberg (Hanahan and Weinberg 2011, 2000)). Microbiomerelated effects stem from basic cellular functions, such as changes to redox homeostasis (Kovács et al. 2019; Smolková et al. 2020; Sári et al. 2020a, b) or changes to cellular metabolism (Sári et al. 2020a, b; Miko et al. 2018; Kovács et al. 2019), via altered gene expression patterns. These primary changes then modulate larger scale events, namely, epithelial-to-mesenchymal transition (Sári et al. 2020b; Miko et al. 2018; Kovács et al. 2019; Buchta Rosean et al. 2019; Ingman 2019; Vergara et al. 2019), cancer cellular movement, invasion, diapedesis and metastasis formation (Kovács et al. 2019; Sári et al. 2020a, b, 2020; Miko et al. 2018; Kovács et al. 2019), angiogenesis (Miko et al. 2018), the modulation of antitumor immunity (Sári et al. 2020a; Miko et al. 2018; Vergara et al. 2019; Sipe et al. 2020; Osman and Luke 2019; Zitvogel et al. 2016; Routy et al. 2018a, 2018b; Gopalakrishnan et al. 2018; Elkrief et al. 2019; Derosa et al. 2020; Hall and Versalovic 2018; Viaud et al. 2014), and tumor-promoting inflammation (Kiss et al. 2020; Yu 2018).

The elementary events act together and the result of their action is dependent on the circumstances. A good example is oxidative stress or the modulation of the immune system. Sustained oxidative stress induces DNA damage and the accumulation of mutations increases the risk for carcinogenic transformation (Smolková et al. 2020; Lau et al. 2008; Jezierska-Drutel et al. 2013). In this case, the dysbiotic microbiome drives local inflammation upon pathological colonization, such as in ovarian carcinoma (Wang et al. 2020) or pancreas adenocarcinoma (Kiss et al. 2020). On the contrary, low oxidative stress, induced by bacterial metabolites, can exert cytostatic (but not cytotoxic) properties, as in the downregulation of NRF2 in breast cancer (Kovács et al. 2019; Sári et al. 2020a, b).

Similar to the aforementioned oxidative stress, the immune system is a double-edged sword. The oncobiome has different effects on the immune system than the eubiome. Bacteria themselves can act as baits for the immune system. Furthermore, immunomodulatory bacterial metabolites were identified in multiple carcinomas (Sári et al. 2020a; Miko et al. 2018) that can fine tune the behavior of the immune system. Hence, the oncobiotic transformation may tune the immune system differently (Zitvogel et al. 2016). The tolerogenic state of the immune system jeopardizes the early elimination of cancer cells, reduces the efficiency of immunotherapy, and reduces oxidative stress (Zitvogel et al. 2016). In contrast, a more immunogenic microbiome supports immunotherapy (Routy et al. 2018a; Gopalakrishnan 2018), but in turn induce higher oxidative stress and increase the risk for mutations and may sustain tumorigenic inflammation (Buchta Rosean et al. 2019; Pagliari et al. 2018; Ochi et al. 2012; Pushalkar et al. 2018; Sethiet al. 2018; Ren et al. 2017).

What can drive oncobiotic transformation? Lifestyle choices are major contributing factors, including smoking (Biedermann 2013), feeding, obesity (Schulz et al. 2014), changes to the diurnal rhythm (Zarrinpar et al. 2016, 2014; Paschos and FitzGerald 2017), aging (Zhang et al. 2019; Saffrey et al. 2014; Singh et al. 2019), underlying diseases such as diabetes (Devaraj et al. 2013), and exercise (Ticinesi et al. 2019). In addition, antibiotic (Friedman et al. 2006) or probiotic use (Mendoza 2019; Ranjbar et al. 2019) are associated with carcinogenesis. Recently, interbacterial signaling was identified, which depends on the release of components of bacterial cells that trigger resistance of the remaining live cells to the noxa that causes bacterial cell death (Bhattacharyya et al. 2020). The involvement of "dead cell signaling" has not been evaluated in controlling the composition of the microbiome. Sensing the numbers of bacteria in the environment (quorum sensing) is also a major player in fine tuning the microbiome ( $\mathrm{Li}$ et al. 2019; Juhász et al. 2017).The microbiome also interferes with all therapeutic modalities, including chemotherapy, radiotherapy, and targeted therapeutic approaches (Bashiardes et al. 2017; Alam et al. 2020; Roy and Trinchieri 2017). Interestingly, while bacteria can interfere with the metabolism or distribution of the elements of therapy (Perales-et al. Puchalt 2018), therapy can modulate the composition of the microbiome.

\section{Oncobiotic transformation in ovarian cancer}

Oncobiosis was identified in several compartments, including vaginal, cervicovaginal (Ness et al. 2003; Nené et al. 2019), upper genital tract (Zhou et al. 2019a; Brewster et al. 2016), ovarian, intratumoral (Wang et al. 2020; Banerjee et al. 2017; Shanmughapriya et al. 2012; Poore et al. 2020), peritoneal (Miao et al. 2020), serum (Kim et al. 2020), and fecal (Mori et al. 2019) compartments (Table 1, Fig. 1). Oncobiosis can lead to lower diversity, 


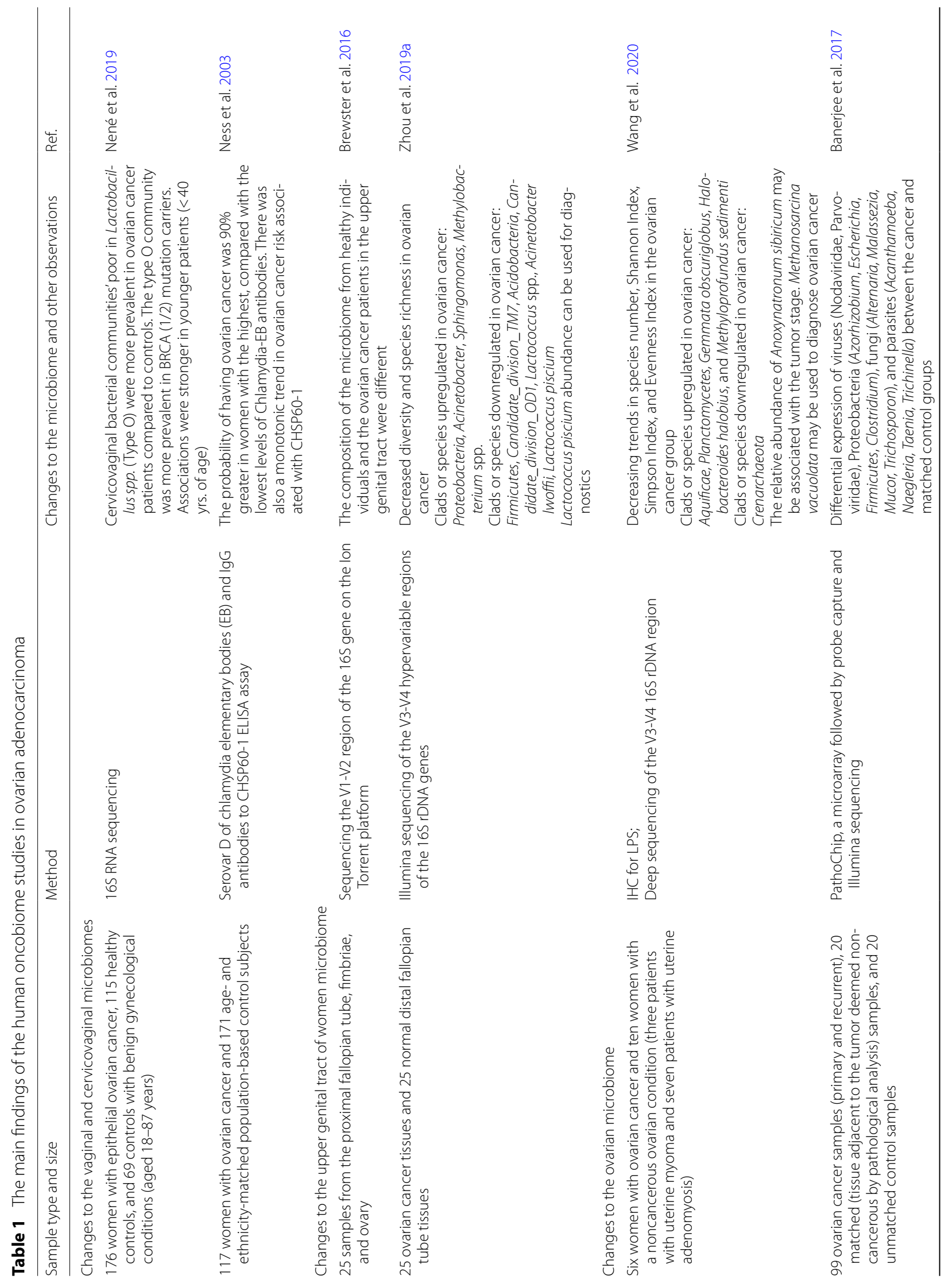




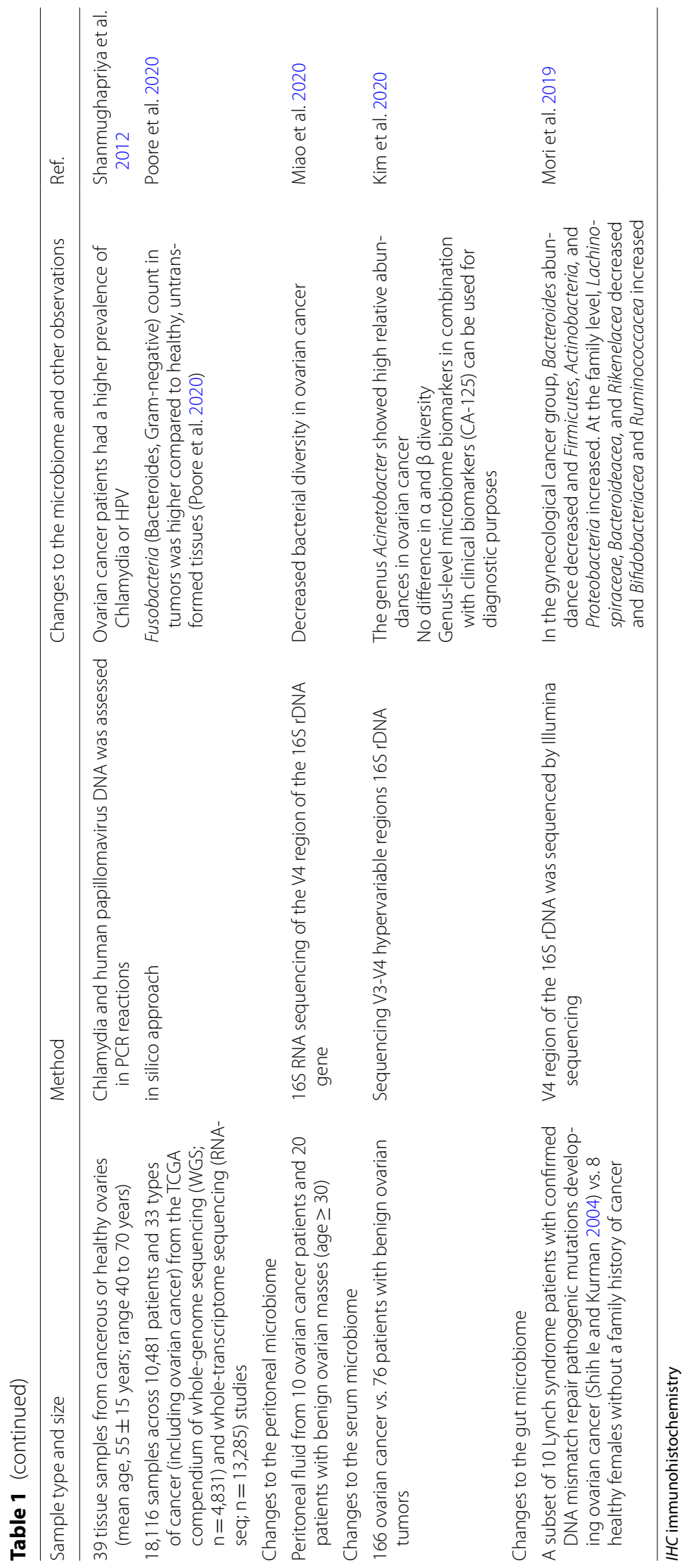




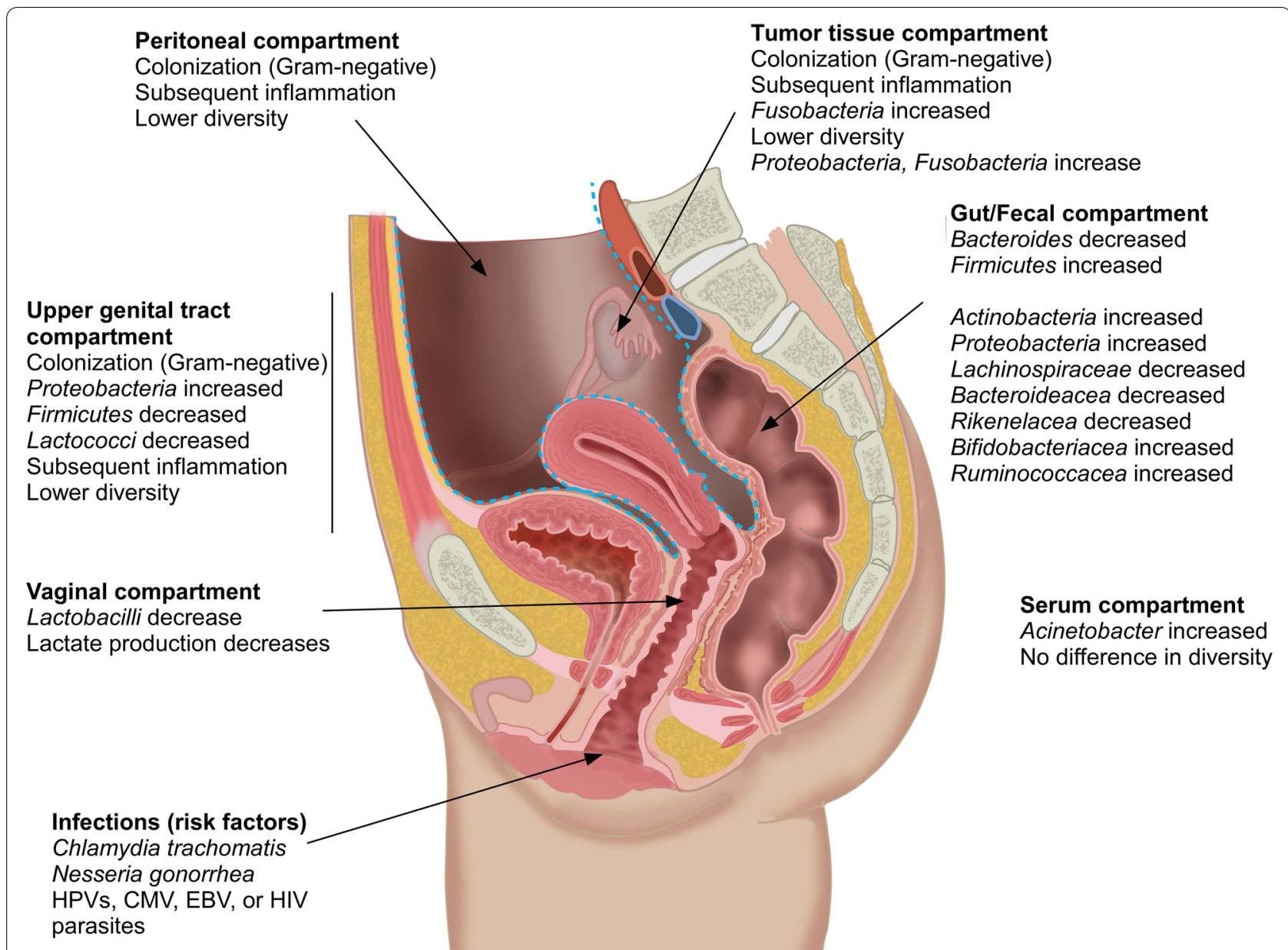

Fig. 1 Changes to microbiome compartments in ovarian cancer. The center figure is taken from https://anatomytool.org/content/sagittal-secti on-female-pelvis-peritoneum as a free image

as in the cases of the intratumoral microbiome [Shannon index, Simpson index, and evenness index decrease (Wang et al. 2020)], the upper genital tract microbiome [Shannon index decrease, while in the Simpson index there is a borderline increase (Zhou et al. 2019a)], and the peritoneal microbiome (Miao et al. 2020). In other compartments, such as the serum, oncobiosis does not interfere with either $\alpha$ and $\beta$ diversity. (Kim et al. 2020). [For the explanation of the diversity indices we refer the reader to (Alpha and beta diversity [http://www.metag enomics.wiki/pdf/definition/alpha-beta-diversity]; Vida et al. 2020)].

In the vaginal and cervicovaginal parts of the genital tract, Lactobacilli act as gatekeepers against bacterial and certain viral vaginal infections by maintaining low $\mathrm{pH}$ and epithelial tight junctions, as well as, producing antimicrobial substances (Laniewski et al. 2020). Importantly, Lactobacilli are protective species against ovarian cancer (Xu et al. 2020). Vaginal communities that are poor in Lactobacillus are more prevalent in ovarian cancer patients compared to controls. Lactobacillus spp. poor communities are more prevalent in BRCA (1/2) mutation carriers, suggesting a role for oncobiosis in enhancing the effects of genetic mutations. Associations are stronger in younger patients ( $<40$ yrs. of age) (Nené et al. 2019).

In the tumor tissue, the Proteobacteria/Firmicutes ratio increases, since the abundance of Proteobacteria increase (Wang et al. 2020; Zhou et al. 2019a). Fusobacteria (Bacteroides) count in tumors is higher compared to healthy, untransformed tissues (Poore et al. 2020). Both Proteobacteria and Fusobacteria are Gram-negative; hence, the microbiome gains more immunogenic character. The oncobiotic peritoneal microbiome is also rich in Gram-negative bacteria (Miao et al. 2020). In contrast, the gut oncobiome is enriched in Gram positive bacteria, as Bacteroides abundance decreased and Firmicutes, Actinobacteria, and Proteobacteria increased in the gut microbiome. At the family level, Lachinospiraceae, 
Bacteroideacea, and Rikenelacea decreased and Bifidobacteriacea, Ruminococcacea increased (Mori et al. 2019).

In addition to oncobiotic transformation, genital pathogens (e.g. Chlamydia trachomatis or Nesseria gonorrhea) increase the risk for ovarian cancer (Ness et al. 2003; Shanmughapriya et al. 2012; Xu et al. 2020; Idahl et al. 2011; Trabert et al. 2019; Xie et al. 2017; Rasmussen et al. 2017; Carvalho and Carvalho 2008). A case report (Vyas 2007) showed the synchronous occurrence of Brucellosis and ovarian cancer, underlining the association between infection of the female genital tract and ovarian cancer. Of note, although Mycobacteria were detected in ovarian cancer specimens and were linked to pathogenesis, recent studies provided strong evidence that Mycobacteria stemmed from external contaminations to samples (Poore et al. 2020; Robinson et al. 2017; Chan et al. 1996). Lactobacilli are key species to protect against vaginal infections and Lactobacillus spp. poor communities increase the risk of ovarian cancer (Nené et al. 2019). Furthermore, viral infections (HPVs, CMV, EBV, or HIV) were shown to interfere with carcinogenesis in ovarian cancer (reviewed in (Łaniewski et al. 2020; Pathak et al. 2020; Levinson et al. 2018)). Besides bacteria and viruses, fungal and parasitic signatures were shown to be associated with ovarian cancer (Banerjee et al. 2017).

An ample set of data suggests that the microbiome drives inflammation and regulates immune responses to support carcinogenesis in ovarian cancer. This is highlighted by the observation that pelvic inflammatory disease is a risk factor for ovarian cancer (Laniewski et al. 2020; Rasmussen et al. 2017, 2013; Mert et al. 2018). Infections of the genital tract are excellent drivers of local inflammation. Inflammation can drive oncogenesis through multiple pathways, involving increased oxidative stress, the resulting DNA damage, and the accumulation of mutations. Pattern recognition receptors TLR2, 4, and 5 respond to bacterial flagellin (Rutkowski et al. 2015) or LPS (Wang et al. 2020, 2014; Kashani et al. 2020; Kelly et al. 2006; Glezerman et al. 1998; Huleihel et al. 1997; Park et al. 2017; Muccioli and Benencia 2014) and have pivotal roles in driving inflammation in ovarian cancer. Allegra and colleagues alluded to an interaction between miRNAs and the microbiome (Allegra et al. 2020). Treatment of ovarian cancer cells with Lactobacillus lactis, a vaginal synbiont, modulates the expression of miR-21 and miR-200b, and, subsequently, TLR4 responsiveness of CAOV-4 cells (Rahbar Saadat 2019). The activation of TLR2, 4, and 5 culminate in the activation of inflammation-associated cytokine signaling pathways in ovarian cancer and the adjacent tissues, leading to the activation of NF-kappa B signaling (Zhou 2019a). Other pattern recognition receptors may be involved in ovarian cancer development (Cheng et al. 2020), but the evidence for their involvement is weak. Tumorassociated macrophages have a pivotal role in driving ovarian cancer development (Xu et al. 2019). The colonization of the peritoneum can drive metastasis formation and likely define the site of metastasis formation in the peritoneum. Furthermore, metastasis to the bowels may involve an interplay between the microbiome of the peritoneal and gastrointestinal (fecal) compartments.

\section{The role of bacterial metabolites in ovarian cancer}

The gut microbiome has a diverse and enormous metabolic capacity due to the large number of bacterial species and the large variability in their proportions (Magnusdottir and Thiele 2017). Bacterial metabolites or components of bacteria can act locally or enter the systemic circulation of the host and exert hormone-like effects at distant sites. Such hormone-like effects were described in the pathology of breast cancer, pancreatic adenocarcinoma, colorectal cancer, gastric cancer, hepatocellular carcinoma (Miko et al. 2016; Miko et al. 2019; Kiss et al. 2020; Kuo et al. 2016; Chen et al. 2016; Shellman et al. 2017; Yoshimoto 2013; Ravnik et al. 2020; Rossi et al. 2020; Sittipo et al. 2019). In this chapter we will review those bacterial metabolites that can potentially have role in the pathogenesis of ovarian cancer. We will review the bacterial metabolism, serum/tissue levels and receptors of these metabolites in ovarian cancer and review the possible involvement of these metabolites in the pathogenesis of ovarian cancer.

It is of note that certain metabolites may have bacterial, human, or sometimes nutritional origin, these cases were identified in the respective chapters discussing the metabolite in question. When metabolomic studies are discussed it should be noted that the source of the metabolites cannot be determined (i.e. bacterial, host or nutritional).

\section{Lipopolysaccharides (LPS)}

Lipopolysaccharides, lypoglycans, and endotoxins are components of the bacterial outer membrane in Gramnegative bacteria (Bertani and Ruiz 2018). LPS molecules have a lipid core, which facilitates membrane attachment, to which polysaccharide chains are joined. LPS essentially protects bacterial cells against external toxins, antibiotics, and bile acids. LPS is highly immunogenic and is a pathogen-associated molecular pattern (PAMP). LPS 
stimulates TLR4 and TLR2 receptors (Bertani and Ruiz 2018; Lu et al. 2008).

In oncobiosis accompanying ovarian cancer, the proportions of Gram-negative bacteria and, therefore, LPS quantity increase in the cancer tissue (Wang et al. 2020). LPS plays a pivotal role in driving inflammation in ovarian cancer (Wang et al. 2020, 2014; Kashani et al. 2020; Kelly et al. 2006; Glezerman et al. 1998; Huleihel et al. 1997; Park et al. 2017; Muccioli and Benencia 2014). LPS can activate cancer cells and tumor-associated macrophages (TAM). The reactivity of cancerous tissue to LPS is higher compared to normal tissues (Glezerman et al. 1998; Huleihel et al. 1997). LPS stimulation of ovarian cancer cells induces phosphatidyl-inositol-3 kinase activation, EMT, and migration marked by the overexpression of N-cadherin, Slug, Vimentin, Snail, $\alpha$-SMA, TCF, MMP2, and MMP9 (Park et al. 2017). The functionality of LPS-induced inflammation is highlighted by the fact that the blockade of TLR4 reduces ovarian cancer proliferation (Kashani et al. 2020) and TLR4 activation promotes proliferation and induces drug resistance (Kelly et al. 2006). The physical presence of certain vaginal microbes, as Lactobacillus lactis, can modulate the responsiveness of TLR4 though modulating the expression of miR-21 and miR-200b and, hence, decrease responsiveness of CAOV-4 ovarian cancer cells to LPS (Rahbar Saadat et al. 2019).

LPS stimulation of TAMs pushes the macrophages towards the M1 profile (Trenti et al. 2018; Wanderley et al. 2018), which is cytotoxic and cytostatic for ovarian cancer cells (Han et al. 1999). The applicability of LPS stimulation to induce and immunogenic destruction of ovarian cancer cells was questioned by recent results showing that, in an experimental model of ovarian cancer, LPS administration did not prolong survival, and, based on the timing of administration, may have even shortened survival (Vindevogel et al. 2016). Taken together, LPS appears to be a procarcinogenic bacterial metabolite.

\section{Lysophospholipids}

Lysophospholipids are by-products of metabolic reactions involved in bacterial membrane homeostasis (Zhang and Rock 2008; Zheng et al. 2017), as well as, are synthesized in the cells of the host. Gram-negative bacteria have high lysophospholipid content (Zhang and Rock 2008; Zheng et al. 2017) and, as stated earlier, the proportions of Gram-negative bacteria increase in ovarian cancer patients (Wang et al. 2020). Their chemical structure differs from general phospholipids. The coneshaped structure of lysophospholipids confers detergentlike properties to these molecules (Zheng et al. 2017). Lysophospholipids are generated under stress conditions, either by phospholipase A2, which removes a fatty acid moiety from position 2 of glycerol, as by-products of phospholipid biosynthesis, or by the release of exogenous lipases (Zheng et al. 2017). Lysophosphatids bind to lysophosphatidic acid receptors (LPAR1-6) (Lin et al. 2010). Lysophosphatids are present in the serum, plasma, and ascites (Ye et al. 2008).

Lysophosphatids impact the behavior of ovarian cancer cells by influencing multiple cancer hallmarks. Lysophosphatidic acid (LPA) and lysophosphatidylserine induce Akt, MAPK, and calcium signaling and LPA induces cell proliferation, migration, and invasion of ovarian cancer cells (Xu et al. 1995; Estrella et al. 2007; Jeong et al. 2012, 2013; Pustilnik 1999; Sengupta et al. 2003; Hurst and Hooks 2009). LPA can upregulate the expression of elements of angiogenesis in ovarian cancer (Lee et al. 2006). Lysophosphatids are upregulated in the plasma of ovarian cancer patients (Fanet al. 2012; Zhang et al. 2013). TLR5 activation enhances the formation of distal metastases in ovarian cancer by reprograming the immune system (Rutkowski et al. 2015). Lysphosphatids are carcinogenic metabolites similar to LPS.

\section{Tryptophan metabolites}

The metabolism of tryptophan, an amino acid, is very complex and intricate. Approximately $4-6 \%$ of tryptophan undergoes bacterial metabolism and yields indolederivatives (Wikoff et al. 2009; Yokoyama and Carlson 1979; Browne et al. 2012; Aidy et al. 2012; Mardinoglu et al. 2015; Gao 2018). Bacterial tryptophan metabolism has multiple arms, as reviewed in (Wikoff et al. 2009; Yokoyama and Carlson 1979; Browne et al. 2012; Aidy et al. 2012; Mardinoglu et al. 2015; Gao et al. 2018). The main receptors for tryptophan-derivatives are aryl hydrocarbon receptor (AHR) and pregnane $\mathrm{X}$ receptor (PXR) (Zelante et al. 2013; Venkatesh et al. 2014; Lamaset al. 2016).

AHR has pivotal roles in immune regulation (Gao et al. 2018; Kim et al. 2018) and low dietary tryptophan leads to immunosuppression (Sonner et al. 2019). Mucosal immunity can be regulated by AHR activation. Therefore, indole-derivatives can impact on the composition of microbiome compartments. As an example, indolderivatives support the growth of Lactobacillus reuteri that, in turn, inhibit the expansion of pathogenic bacteria (Zelante et al. 2013; Shi et al. 2007; Qiu et al. 2012; Zhang et al. 2017) and protect against ovarian cancer (Nené et al. 2019). In addition, certain Lactobacilli can utilize tryptophan as an energy source. Therefore, a tryptophanrich diet can improve Lactobacillus viability and induce proliferation (Zelante et al. 2013).

Tryptophan levels and indolepropionic acid (a bacterial tryptophan metabolite) decrease in the serum of ovarian 
cancer patients (Plewa et al. 2017; Hilvo et al. 2016; Zhou et al. 2010; Zhang et al. 2012; Ke et al. 2015), a trend that is aggravated by increased stage of the disease (Ke et al. 2015). In good agreement with that, urinary indolepropionic acid concentrations correlate with the presence of epithelial ovarian cancer compared to healthy controls (Zhang et al. 2013). Apparently, indole-derivatives are antineoplastic and their production decreases in ovarian cancer.

\section{Other bacterial metabolites with potential involvement in ovarian cancer}

Other bacterial metabolites were shown to affect other cancers, nevertheless, based on the currently available data, their involvement in ovarian cancer was ambiguous. For metabolism and species information we refer the readers to reviews (Miko et al. 2019; Kiss et al. 2020; Wortham et al. 2007; Michael et al. 2018; Ridlon et al. 2006; Ridlon and Bajaj 2015; Gerard 2013; Ramirez-Perez et al. 2017).

Short chain fatty acids (SCFAs), encompassing acetate, propionate, butyrate, and lactate were cytostatic in numerous cancers. The reference concentration of SCFAs in the human serum is in the range of 10-100 $\mu \mathrm{M}$ (Clausen et al. 1991; Jakobsdottir et al. 2013; Ktsoyan et al. 2016) and may reach locally to $1 \mathrm{mM}$ (Pryde et al. 2002). SCFAs act on free fatty acid receptors (FFARs) and AHR (Jin et al. 2017). Most SCFAs can act as energy sources in cells (Sittipo et al. 2019) or may inhibit histone deacetylases and through that, can modulate epigenetics (Shimazu 2013; Menzies et al. 2016; Fellows and Varga-Weisz 2020). SCFAs impact on the $\mathrm{pH}$ of the colon, modulate the immune system and, as a consequence, influence the composition of the colon microbiome (Fachi et al. 2020). SCFA production probably plays role in quorum sensing, as suggested by in vitro experiments ( $\mathrm{Li}$ et al. 2020; Ge et al. 2019). When ovarian cancer cells were treated with SCFAs in superphysiological, low millimolar concentrations $(1-5 \mathrm{mM})$ in in vitro experiments, SCFAs exerted cytostatic pro-apoptotic (Terao et al. 2001; Krupitza et al. 1995), anti-EMT (Mrkvicova 2019) features and inhibited invasiveness (Krupitza et al. 1996) and induced senescence (Terao 2001; Yabushita and Sartorelli 1993; Langdon et al. 1988). These results suggest that SCFAs can potentially be antineoplastic. Contradicting these beneficial effects, metabolomic studies showed that hydroxybutyric acid (Hilvo et al. 2016), lactate and pyruvate (Kyriakides et al. 2016; Boss et al. 2000; Fong et al. 2011) increased in tumors and cyst fluid of patients. The bacterial pathways generating SCFAs (pentose phosphate pathway, starch and sucrose metabolism, fructose and mannose, pyruvate metabolism, galactose metabolism, and glycan degradation) (Wang et al. 2020) are upregulated in the tumors of ovarian cancer patients, as well as, in the tumor cells themselves (Turkoglu et al. 2016).

Polyamines (e.g. spermine, spermidine) are organic molecules with more than two amine groups. Polyamines support bacterial growth and biofilm formation and through these, in pathogenic species, polyamines are virulence factors (Michael et al. 2018) and quorum sensing signals (Rattanaphan et al. 2020; Inaba et al. 2020). Some circulating polyamines may be of bacterial, human, and/ or dietary origin (Ramos-Molina et al. 2019). Polyamines and putrescine are usually linked with tumorigenesis in cancers other than ovarian cancer. A serum metabolome study demonstrated that polyamine metabolism was dysregulated in ovarian cancer (Zhou 2010). Spermine and spermidine levels in erythrocytes, plasma, and urine of ovarian cancer patients increase compared to healthy, age-matched controls, suggesting a systemic increase in these metabolites in ovarian cancer (Hayase et al. 1985; Lawton et al. 1989; Chanda and Ganguly 1995). Similarly, urinary $N^{1}, N^{12}$-diacetylspermine levels are higher in patients with malignant ovarian tumors compared to patients with benign tumors (Niemi et al. 2017). Furthermore, the probability/frequency of increased blood polyamine levels is in line with the progression of ovarian cancer.

Secondary bile acids (lithocholic acid (LCA), deoxycholic acid (DCA), and ursodeoxycholic acid (UDCA)) are bacterial transformation products of hepatic primary bile acids taking place in the intestines. Bile acids undergo enterohepatic circulation (hepatic synthesis and secretion to duodenum, intestinal transformation, reabsorption and return to the liver) that is hampered in ovarian cancer. The enterohepatic circulation of bile acids is modified in ovarian cancer; bile acid reabsorption is hampered (Larsen et al. 2019) and less bile acids appear in the ascites (Hedenborg et al. 1988). A fraction of the reabsorbed bile acids enter the systemic circulation (Marshall et al. 2016) (total bile acid concentration in the serum is $>5 \mu \mathrm{M}$ in a healthy individual) and that bile acid pool can exert hormone-like, systemic effects (Miko et al. 2019, 2018; Ravnik et al. 2020; Watanabe et al. 2006; MahmoudianDehkordi 2019; Sarin et al. 2019; Tang et al. 2019). The serum concentration of bile acids is submicromolar for deoxycholic acid and $100-300 \mathrm{nM}$ for ursodeoxycholic acid, while LCA is present in much lower concentrations in serum, $30 \mathrm{nM}$ (Miko et al. 2018). Bile acids can impact on the composition of the microbiome (Tsuei et al. 2014; Merritt and Donaldson 2009; Garcia-Quintanilla et al. 2006; Prieto et al. 2006, 2004; Kandell and Bernstein 1991; Schaffler and Breitruck 2018; Sorg and Sonenshein 2010) and 
bile acids can facilitate bacterial translocation into tissues (Slocum et al. 1992). Bile acid signaling in humans is very complex, with multiple receptors. Receptors for bile acids include farnesyl-X-receptor (FXR), liver-X receptor (LXR), Takeda G Protein-Coupled Receptor 5 (TGR5), constitutive androstane receptor (CAR), vitamin $\mathrm{D}$ receptor (VDR), pregnane $\mathrm{X}$ receptor (PXR), sphingosine-1-phosphate receptor 2 (S1PR2), and muscarinic M2,3 receptors. Apart from TGR5, S1PR2, M2, and M3, all receptors are nuclear receptors.

Most in vitro cellular studies assessed bile acids at superphysiological concentrations $(0.05-400 \quad \mathrm{mM})$ (Horowitz et al. 2007; Schuldes et al. 2001; Jin et al. 2018). At these superphysiological concentrations, bile acids are cytotoxic, antineoplastic in cell models (Horowitz et al. 2007; Schuldes et al. 2001), mostly due to changing the biophysical properties of the cell membrane and damage to DNA (Schuldes et al. 2001), although, whether these changes would occur at physiological concentrations require further studies. The concentrations of most bile acids as 3b-hydroxy-5-cholenoic acid, glycoursodeoxycholic acid, and deoxycholic acid (Ke 2015), taurochenodeoxycholic acid (Fan et al. 2016) decrease in ovarian cancer patients. Bile acid receptors have variable effects on ovarian cancer cells. The activation of a bile acid receptor LXR reduces the proliferation of ovarian carcinoma cells (Scoles et al. 2010; Rough et al. 2010) and improves the efficacy of anti-VEGF therapy (Curtarello et al. 2019). In contrast to that, the inhibition of the PXR pathway induces ovarian cancer cell proliferation (Masuyama et al. 2016). Furthermore, PXR or CAR activation contributes to chemoresistance and proliferation (Wang et al. 2014; Gupta et al. 2008; Chen et al. 2012). Taken together, these results suggest that bile acids may have cytostatic properties on ovarian cancer cells, and this effect is lost or reduced in ovarian cancer patients. However, the role of the bile acid receptors calls for further detailed investigations.

\section{Modulating the oncobiome in ovarian cancer Antibiotics}

Topical or systemic antibiotic treatment has a strong impact on the composition of the microbiome. Antibiotic treatment impacts the frequency and recurrence of breast cancer (Friedman et al. 2006; Kirkup et al. 2019, 2020; Wirtz et al. 2013). In the case of pancreatic adenocarcinoma where bacterial colonization of the pancreas is a major driver of carcinogenesis (Kiss et al. 2020) similar to ovarian cancer, antibiotic treatment was beneficial in animal models (Thomas et al. 2018). Pathogen colonization influences ovarian carcinogenesis, indicating that antibiotic use in ovarian cancer may inhibit cancer cell movement and metastasis formation. However, we are not aware of any dedicated in vivo study to assess this possibility, nevertheless, the literature suggests that antibiotic treatment may impact on the gut microbiome and, hence modulate the polarization of the immune system, and through that inflammation promoting ovarian cancer (Cheng et al. 2020).

Available studies used antibiotics and antimycotics as single agents or in drug combinations to directly act on cancer cells in in vitro models to improve chemotherapy. Lamb and colleagues (Lamb et al. 2015) showed that a set of antibiotics (erythromycins, tetracyclines, glycylcyclines, and chloramphenicol) can block cell proliferation and reduce the proportions of ovarian cancer stem cells. Minocycline, as a single agent, can also reduce the proliferation of ovarian cancer cells by interfering with energy-sensing pathways and proliferative signaling (Ataie-Kachoie et al. 2013a, b, 2015; Pourgholami et al. 2013). Ciprofloxacin can also act as a single agent to reduce cancer cell proliferation (Kloskowski et al. 2010). In addition, ciprofloxacin prophylaxis in taxol-based chemotherapy regimens prevents febrile neutropenia and sepsis during chemotherapy (Carlson et al. 1994). Finally, salinomycin can impair cancer cell proliferation by inhibiting proliferation, inducing apoptosis, blocking EMT, and reducing stem-ness (Zhang et al. 2012; Parajuli et al. 2013a, b; Chung et al. 2016; Kaplan and Teksen 2016; Li et al.2017; Lee et al. 2017). Several of these antibiotics can bind to mitochondrial complex I and interfere with cellular energetics (Lamb et al. 2015) to interfere with the behavior of cancer cells.

Antibiotics can be used as a component of drug combinations also. Tigecycline (Tan et al. 2017), clarithromycin (Zhou et al. 2019b), amphotericin B (Kojima et al. 1994), valinomycin (Daoud and Forde 1991), and salinomycin (Michalak et al. 2020) can be used in combination with cisplatin. Moreover, antibiotics can be used to counteract cisplatin resistance, a major issue in ovarian cancer chemotherapy, as evidenced in murine models (Chambers et al. 2020). Minocycline can potentiate topoisomerase inhibition (Huang et al. 2018).

Interestingly, a study by Wang et al. (Wang et al. 2020) showed that the resident bacteria in ovarian cancer tissue produced antibiotics. In particular, the biosynthesis of butirosin, neomycin, vancomycin, streptomycin, and ansamycins were different in cancerous tissues compared with healthy control tissues. The biological impact of this finding has not been assessed to date.

Although many studies suggest the potential applicability of antibiotics in cancer therapy, Xu and colleagues (Xu et al. 2019) showed that combination treatment of Balb/c mice grafted with SKOV4 ovarian cancer cells with ampicillin, vancomycin, neomycin, and metronidazole promoted the growth and invasiveness of grafts. Thus, the 
applicability of antibiotics should be carefully assessed and considered in a clinical setting. In addition, the applicability of oral or vaginal probiotics should be considered (Brewster et al. 2016; Chase et al. 2015; Champer et al. 2018), although experimental data is missing.

\section{Nutrients and diet}

Nutrition modulates the composition of the microbiome along with other lifestyle elements. Obesity is a risk factor for ovarian cancer (Leitzmann et al. 2009) and the ketogenic diet was shown to reduce central obesity and reduce insulin levels in ovarian cancer patients (Cohen et al. 2018). Animal fat (Shu et al. 1989) and retinol (Zhang et al. 2004) consumption increases the risk for ovarian cancer (Shu et al. 1989; Zhang et al. 2004), while vegetable (Shu et al. 1989), fiber (Zhang et al. 2004), carotene (Zhang et al. 2004), vitamin C (Zhang et al. 2004), and vitamin $\mathrm{E}$ (Zhang et al. 2004) consumption is protective in a dose-dependent fashion. Nutrients (e.g. polyamines (Ramos-Molina et al. 2019; Tofalo et al. 2019) or tryptophan (Gao et al. 2018; Lin et al. 2017)) can directly impact inflammation, a driver of carcinogenesis in ovarian cancer (Madeo et al. 2020). Polyunsaturated fatty acids reduce the expression of key chemokines (e.g. IL-6) in ovarian cancer-associated. Lactobacilli seem to be unique in the human vaginal flora (Miller et al. 2016) and are protective against ovarian cancer (Nené et al. 2019). In good agreement with this, animal-derived nutrients increase the risk of cervical cancer by reducing Lactobacilli in the vaginal flora (Seo et al. 2016) and tryptophan supplementation that support the growth of certain Lactobacilli by serving as an energy source can improve Lactobacillus viability and induce proliferation (Zelante et al. 2013).

\section{Interference with chemotherapy}

The microbiome can interfere with cancer chemotherapy and management strategies. In fact, the interactions form a circuit, where (1) the microbiome or oncobiome interferes with the metabolism of chemotherapeutic drugs, modulates the immune system, and interferes with the side effects of drugs, and, conversely, (2) therapy modulates the composition and behavior of the microbiome. We will review the interference between the microbiome and the individual elements of the chemotherapy regimen used in ovarian cancer. Bacterial metabolites themselves can modulate the effectiveness of chemotherapeutic agents that is summarized in Table 2.

To date, there is no data on the microbial metabolism of medically used taxols. Paclitaxel can bind to and activate TLR4 receptors to reprogram the immune system (Byrd et al. 1999). This may be the reason why the colonization of the tumor with Salmonella typhimurium or Porphyromonas gingivalis (Miyake et al. 2019; Woo et al. 2017) can interfere with paclitaxel efficiency in cancers other than ovarian cancer. In the same manner, bacterial LPS may confer resistance to Taxol in macrophages (Sweet and Hume 1996), hence, colonization of ovarian cancer tissue by LPS-rich, Gram-negative bacteria can impact on local Taxol effectiveness. Taxanes can interfere with the invasiveness and infectivity of Klebsiella pneumoniae (Oelschlaeger and Tall 1997) and Campylobacter jejuni (Biswas et al. 2000).

Platinum drugs can crosslink (Dedduwa-Mudalige and Chow 2015) and do oxidative damage to nucleic acids in bacterial, or in human cells (Beaufay et al. 2020). Cisplatin and carboplatin, therefore, exert bacteriostatic properties on Acinetobacter, Mycobacteria, and Pseudomonas aeruginosa (Yuan et al. 2018; Gajdács and Spengler 2019; McCarron et al. 2012; Zhang et al. 2011) and other pathogens (Hummell and Kirienko 2020). Cisplatin kidney

Table 2 Interactions between bacterial metabolites and drugs relevant in ovarian cancer chemotherapy

\begin{tabular}{|c|c|c|c|}
\hline Drug & Metabolite & Effect & Ref. \\
\hline \multirow[t]{2}{*}{ Cisplatin } & Spermine, spermidine & induce cisplatin resistance & $\begin{array}{l}\text { Marverti et al. 2005; Marverti et al. 2004; Marvert } \\
\text { et al. 2001; Marverti et al. 1997; Hector et al. } \\
\text { 2004; Desiderio et al. } 1997\end{array}$ \\
\hline & Butyrate and valproic acid & & $\begin{array}{l}\text { Mrkvicova et al. 2019; Wasserman et al. 1989; } \\
\text { Sajadpoor et al. } 2018\end{array}$ \\
\hline Paclitaxel & LPS & $\begin{array}{l}\text { TLR4 activation induces pacli- } \\
\text { taxel chemoresistance }\end{array}$ & $\begin{array}{l}\text { Kelly et al. 2006; Edwardson et al. 2017; Huang } \\
\text { et al. 2014; Szajnik et al. } 2009\end{array}$ \\
\hline \multirow[t]{3}{*}{ Doxorubicin/Adriamycin } & Taurochenodeoxycholate & sensitizes resistant cells & Schuldes et al. 2001 \\
\hline & Butyrate and valproic acid & & Wasserman et al. 1989 \\
\hline & Spermine & induces Doxorubicin resistance & Schuldes et al. 2001 \\
\hline Niraparib & Butyrate and valproic acid & sensitizes resistant cells & Booth et al. 2018 \\
\hline Topoisomerase II inhibitors (Topolli) & Spermine, spermidine & sensitizes cells to Topolli & Desiderio et al. 1997 \\
\hline Mitomycin & Taurochenodeoxycholate & sensitizes & Schuldes et al. 2001 \\
\hline
\end{tabular}

Topolli -Topoisomerase II inhibitor 
toxicity can be prevented via limiting uremic toxins production by probiotics, such as Lactobacillus salivarius BP121 (Lee et al. 2020), a mixture of Lactobacillus plantarum plantarum, Lactobacillus paracasei paracasei, and Streptococcus salivarius, or Streptococcus thermophilus (Lee et al. 2020). Cisplatin administration compromises epithelial barriers, leading to bacterial translocation (Perales-Puchalt et al.2018). Cisplatin resistance can be alleviated by co-treatment with antibiotics (Tan et al. 2017; Zhou et al. 2019b; Kojima et al. 1994; Daoud and Forde 1991; Michalak et al. 2020; Chambers et al. 2020).

Bacteria can metabolize TopoII inhibitors through $\beta$-glucuronidase enzymes (Roberts et al. 2013; Wallace et al. 2015; Bhatt et al. 2020), a key factor influencing TopoII inhibitor availability (Bhatt et al. 2020) and toxicity (Roberts et al. 2013). In fact, $\beta$-glucuronidase enzymes can deconjugate and reactive estrogens and, hence, increase estrogen recirculation (Flores et al. 2012; Baker et al. 2017; Ervin et al. 2019) suggesting a link between bacterial estrogen recycling and TopoII inhibitor availability. TopoII inhibitors have bacteriostatic properties (Patel et al. 1998) and, not surprisingly, TopoII inhibitors modulate the gut microbiome. Irinotecan treatment in rats increased the abundance of clostridial clusters I and XI and Enterobacteriaceae, while total bacteria, Clostridium cluster VI, and the Bacteroides-group decreased. These effects were prevented by oral glutamine administration (Lin et al. 2012). TopolI inhibitors interfere with TLR4 (Wardill et al. 2016) and SCFA (Irinotecan 2006; Encarnação et al. 2018; Lin 2014) signaling. The microbiome plays a key role in mediating the severity of TopoII inhibitor-induced mucositis (Ribeiro et al.2016; Pedroso et al. 2015; Wang et al.2019), which can be ameliorated by Escherichia coli Nissle 1917 (a probiotic) (Wang et al. 2019) or butyrate (Encarnação et al. 2018) and its prebiotics (Lin et al. 2014). The involvement of butyrate demonstrates the contribution of SFCA signaling.

Anthracyclines (e.g. Doxorubicin) are biosynthesized by Streptomyces strains and are used as intercalating agents in cytostatic therapy. Anthracyclines can act as antibiotics too (Cox et al. 2014), for example, anthracyclines can inhibit the growth of Acinetobacter species (McCarron et al. 2012). Multiple bacterial species can metabolize and inactivate anthracyclines (Parajuli et al. 2018; Dhakal et al. 2018; Zabala et al. 2013). Furthermore, anthracycline treatment can facilitate the loss of the intestinal barrier, bacterial translocation and bacterial entry to secondary lymphoid organs (Alexander 2017).

The silencing of PARP1 increases the diversity of the gut microbiome (Vida et al. 2018; Larmonier et al. 2016), indicating that PARP inhibitors may also increase microbiome diversity. PARP enzymes play a role in TLR4 and

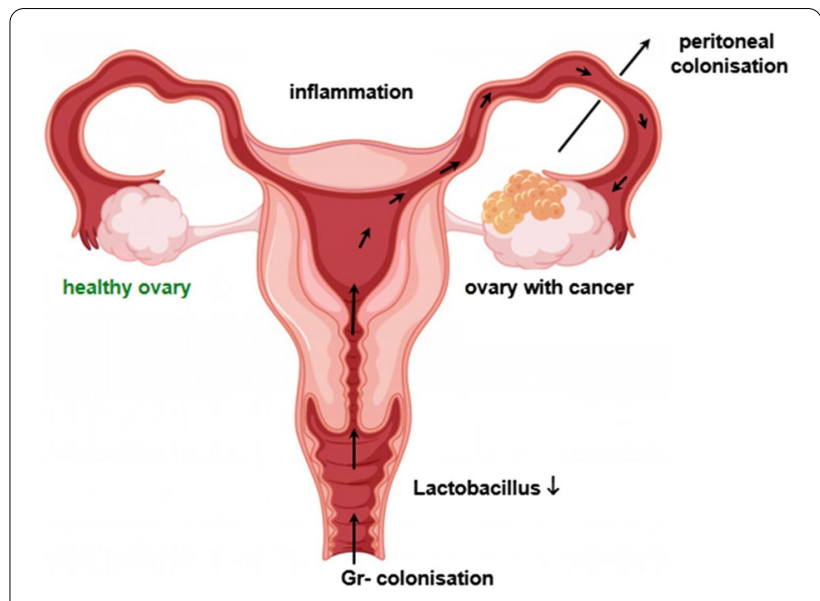

Fig. 2 Bacterial colonization of the upper genital tract as a risk factor for ovarian cancer. In black, the microbial risk factors of ovarian cancer. The image is a free-use image from https://image. freepik.com/free-vector/woman-ovarian-cancer-concept-drawing_ 1308-15806.jpg

5 (Liaudet et al.2002; Zerfaoui et al. 2010), AHR (DianiMoore et al. 2010; Macpherson et al. 2013), and SCFAs signaling through AHR (Jin et al. 2017).

Bevacizumab is a monoclonal antibody targeting VEGF to inhibit vascularization. Bevacizumab is the only tool in targeted therapy to be applied in ovarian cancer. Nevertheless, there are novel, experimental immunological approaches in the treatment of ovarian cancer adoptive cell transfer (ACT) (Rosenberg et al. 2008; Kershaw et al. 2006), Chimeric antigen receptor (CAR) T-cell therapy (CAR-T) (Schepisi 2021), dendritic cell vaccines (Zhang et al. 2020), immune-checkpoint blockade that aim to enhance $T$ cell responses (Schepisi 2021). The effectiveness of therapies involving the activation of the immune system depend on the composition and immunogenic properties of the microbiome (Routy et al. 2018a; Vetizou et al. 2015; Sivan et al. 2015; Matson et al. 2018; Innao et al. 2020; Brandi and Frega 2019; Sun et al. 2020). It should be noted that ovarian cancer-specific microbiome data is missing.

\section{Conclusions}

Current data support the oncobiosis of multiple microbiome compartments in ovarian cancer. Vaginal infections and the colonization of the upper genital tract seem to play important roles in the development of ovarian cancer (Fig. 2) primarily by supporting tumorpromoting inflammation. We provided evidence that signaling through bacterial metabolites play a role in the pathogenesis of ovarian cancer, a set of proinflammatory metabolites (LPS, lysophosphatides) are 
upregulated, while tryptophan metabolites were downregulated that have antineoplastic features. It should be noted that further studies are needed to define the involvement of metabolite signaling in ovarian cancer.

The association of oncobiosis with ovarian cancer implies the possible use antibiotics or probiotics to mitigate the side effects of chemotherapy (Wang et al. 2019) or eradicate the colonizing bacterial species. Along the same lines, supplementing chemotherapy in hyperthermic intraperitoneal chemotherapy should be considered. To our surprise, such studies are largely missing, despite the fact that the literature discusses numerous hypotheses (Brewster et al. 2016). Probiotics are frequently used to treat banal vaginal infections. Therefore, conducting studies of these agents in relation to ovarian cancer would be straight forward, similar to assessing the use of antibiotics in ovarian cancer.

Another field, where bacterial dysbiosis and metabolite signaling can be exploited, is therapy and diagnostics. There are numerous studies in the literature indicating that microbiome profiles in the intratumoral area (Wang et al. 2020; Poore et al. 2020), genital tract (Wang et al. 2020; Zhou et al. 2019a), the serum (Kim et al. 2020), or the peritoneum (Miao 2020) can be exploited as biomarkers to diagnose ovarian cancer. Metabolomics studies also revealed exploitable biomarkers (Turkoglu et al. 2016). Beyond early diagnostics, these biomarkers can be used for screening, prognosis, patient stratification (e.g. for drug effectiveness), and prognosis. The practical applicability of bacterial metabolite signaling in view of our current understanding of bacterial metabolite signaling warrant future studies.

\section{Search strategy and selection criteria}

References to this review were identified through the prior knowledge of the authors that was complemented by systematic search of Pubmed by using the combinations "microbiome-ovarian cancer", "ovarian cancer-metabolomics". Species information, bacterial metabolism was described based on the prior knowledge of the authors and were updated through Pubmed search. Pubmed search was performed with the name of bacterial metabolites + ovarian cancer, name of the metabolite receptor + ovarian cancer. Articles published in English were included with no restriction on publication date.

\section{Acknowledgments}

The authors are grateful to Ms. Judit Fazekas-Paragh (University of Debrecen, University and National Library, Department of Education and Research Support) for helping the authors in acquiring full text literature.

\section{Authors' contributions}

All authors participated in writing and revising the manuscript. The figures were by AS and PB. All authors read and approved the final manuscript.
Funding

Our work was supported by grants from the NKFIH (K123975 and GINOP-2.3.215-2016-00006 to PB, PD124110 and FK128387 to EM, K120669 to KU). EM is supported by the Bolyai Fellowship from the Hungarian Academy of Sciences and by the ÚNKP-20-5-DE-96 New National Excellence Program of the Ministry of Human Capacities. The research was supported by the Thematic Excellence Programme (TKP2020-IKA-04) of the Ministry for Innovation and Technology in Hungary. KU was supported by National Research, Development and Innovation Office EFOP-3.6.2-16-2017-00006.

\section{Availability of data and materials}

Not applicable.

\section{Declarations}

Ethical approval and consent to participate

Not applicable.

\section{Consent for publication}

Not applicable.

\section{Competing interests}

The authors declare no conflict of interest.

\section{Author details}

${ }^{1}$ Department of Medical Chemistry, Faculty of Medicine, University of Debrecen, Debrecen 4032, Hungary. ${ }^{2}$ Department of Gynecology and Obstetrics, Faculty of Medicine, University of Debrecen, Egyetem tér 1, Debrecen 4032, Hungary. ${ }^{3}$ Department of Medical Microbiology, Faculty of Medicine, University of Debrecen, Debrecen 4032, Hungary. ${ }^{4}$ MTA-DE Lendület Laboratory of Cellular Metabolism, Debrecen 4032, Hungary. ${ }^{5}$ Research Center for Molecular Medicine, Faculty of Medicine, University of Debrecen, Debrecen 4032, Hungary.

Received: 17 January 2021 Accepted: 22 March 2021

Published online: 01 April 2021

\section{References}

Alexander JL, et al. Gut microbiota modulation of chemotherapy efficacy and toxicity. Nat Rev Gastroenterol Hepatol. 2017;14:356-65.

Allegra A, Musolino C, Tonacci A, Pioggia G, Gangemi S. Interactions between the MicroRNAs and Microbiota in cancer development: roles and therapeutic opportunities. Cancers (Basel). 2020;12:E805.

Alpha and beta diversity [Internet]. http://www.metagenomics.wiki/pdf/ definition/alpha-beta-diversity.

Ataie-Kachoie P, Badar S, Morris DL, Pourgholami MH. Minocycline targets the NF-KB Nexus through suppression of TGF- $\beta 1$-TAK1-IKB signaling in ovarian cancer. Mol Cancer Res. 2013a;11:1279-91.

Ataie-Kachoie P, Morris DL, Pourgholami MH. Minocycline suppresses interleukine-6, its receptor system and signaling pathways and impairs migration, invasion and adhesion capacity of ovarian cancer cells: in vitro and in vivo studies. PLoS ONE. 2013b;8:e60817.

Ataie-Kachoie P, Pourgholami MH, Bahrami BF, Badar S, Morris DL. Minocycline attenuates hypoxia-inducible factor-1 a expression correlated with modulation of p53 and AKT/mTOR/p70S6K/4E-BP1 pathway in ovarian cancer: in vitro and in vivo studies. Am J Cancer Res. 2015;5:575-88.

Baker JM, Al-Nakkash L, Herbst-Kralovetz MM. Estrogen-gut microbiome axis: physiological and clinical implications. Maturitas. 2017;103:45-53.

Banerjee S, et al. The ovarian cancer oncobiome. Oncotarget. 2017;8:36225-45. Banks E. The epidemiology of ovarian cancer. Methods Mol Med. 2001;39:3-11.

Bashiardes S, Tuganbaev T, Federici S, Elinav E. The microbiome in anti-cancer therapy. Semin Immunol. 2017;32:74-81.

Beaufay $F$, et al. Polyphosphate functions in vivo as an iron chelator and fenton reaction inhibitor. MBio. 2020. https://doi.org/10.1128/mBio.01017-20. 
Bergamini A, Bocciolone L, Fodor A, Candiani M, Mangili G. Management of recurrent ovarian cancer: when platinum-based regimens are not a therapeutic option. Int J Gynecol Cancer. 2019;29:1431-6.

Bertani B, Ruiz N. Function and biogenesis of lipopolysaccharides. EcoSal Plus. 2018. https://doi.org/10.1128/ecosalplus.ESP-0001-2018.

Bhatt AP, et al. Targeted inhibition of gut bacterial $\beta$-glucuronidase activity enhances anticancer drug efficacy. Proc Natl Acad Sci U S A. 2020;117:7374-81.

Bhattacharyya S, Walker DM, Harshey RM. Dead cells release a'necrosignal'that activates antibiotic survival pathways in bacterial swarms. Nat Commun. 2020;11:4157.

Biedermann L, et al. Smoking cessation induces profound changes in the composition of the intestinal microbiota in humans. PLOS ONE. 2013;8:e59260.

Biswas D, Itoh K, Sasakawa C. Uptake pathways of clinical and healthy animal isolates of Campylobacter jejuni into INT-407 cells. FEMS Immunol Med Microbiol. 2000;29:203-11.

Booth L, Roberts JL, Rais R, Poklepovic A, Dent P. Valproate augments Niraparib killing of tumor cells. Cancer Biol Ther. 2018;19:797-808.

Boss EA, et al. High-resolution proton nuclear magnetic resonance spectroscopy of ovarian cyst fluid. NMR Biomed. 2000;13:297-305.

Brandi G, Frega G. Microbiota: overview and implication in immunotherapybased cancer treatments. Int J Mol Sci. 2019. https://doi.org/10.3390/ ijms20112699.

Brewster WR, Ko EM, Keku TO. An evaluation of the microbiota of the upper genital tract of women with benign changes and epithelial ovarian cancer. J Clin Oncol. 2016;34:5568-5568.

Browne CA, Clarke G, Dinan TG, Cryan JF. An effective dietary method for chronic tryptophan depletion in two mouse strains illuminates a role for 5-HT in nesting behaviour. Neuropharmacology. 2012;62:1903-15.

Buchta Rosean C, et al. Preexisting commensal dysbiosis is a host-intrinsic regulator of tissue inflammation and tumor cell dissemination in hormone receptor-positive breast cancer. Cancer Res. 2019;79:3662-75.

Burger RA, et al. Incorporation of bevacizumab in the primary treatment of ovarian cancer. N Engl J Med. 2011;365:2473-83.

Byrd CA, et al. Heat shock protein 90 mediates macrophage activation by Taxol and bacterial lipopolysaccharide. Proc Natl Acad Sci U S A. 1999;96:5645-50

Carlson JW, et al. Chemoprophylaxis with oral ciprofloxacin in ovarian cancer patients receiving taxol. Gynecol Oncol. 1994;55:415-20.

Carlson JW, et al. Serous tubal intraepithelial carcinoma: its potential role in primary peritoneal serous carcinoma and serous cancer prevention. J Clin Oncol. 2008;26:4160-5.

Carvalho JP, Carvalho FM. Is Chlamydia-infected tubal fimbria the origin of ovarian cancer? Med Hypotheses. 2008;71:690-3.

Chambers LM, et al. Disruption of the gut microbiota attenuates epithelial ovarian cancer sensitivity to cisplatin therapy. bioRxiv. 2020. https://doi. org/10.1101/2020.06.16.155226.

Champer $\mathrm{M}$, et al. The role of the vaginal microbiome in gynaecological cancer. BJOG. 2018;125:309-15.

Chan PJ, Seraj IM, Kalugdan TH, King A. Prevalence of mycoplasma conserved DNA in malignant ovarian cancer detected using sensitive PCR-ELISA. Gynecol Oncol. 1996;63:258-60.

Chanda R, Ganguly AK. Diamine-oxidase activity and tissue di- and poly-amine contents of human ovarian, cervical and endometrial carcinoma. Cancer Lett. 1995;89:23-8.

Chang SJ, Bristow RE, Ryu HS. Impact of complete cytoreduction leaving no gross residual disease associated with radical cytoreductive surgical procedures on survival in advanced ovarian cancer. Ann Surg Oncol. 2012;19:4059-67.

Chase D, Goulder A, Zenhausern F, Monk B, Herbst-Kralovetz M. The vaginal and gastrointestinal microbiomes in gynecologic cancers: a review of applications in etiology, symptoms and treatment. Gynecol Oncol. 2015;138:190-200.

Chen $Y$, et al. Nuclear receptors in the multidrug resistance through the regulation of drug-metabolizing enzymes and drug transporters. Biochem Pharmacol. 2012;83:1112-26.

Chen MC, Chen YL, Wang TW, Hsu HP, Lai MD. Membrane bile acid receptor TGR5 predicts good prognosis in ampullary adenocarcinoma patients with hyperbilirubinemia. Oncol Rep. 2016;36:1997-2008.
Cheng $\mathrm{H}$, et al. Opportunities and challenges of the human microbiome in ovarian cancer. Front Oncol. 2020;10:163.

Chung $\mathrm{H}$, et al. The effect of salinomycin on ovarian cancer stem-like cells. Obstet Gynecol Sci. 2016;59:261-8.

Clausen MR, Mortensen PB, Bendtsen F. Serum levels of short-chain fatty acids in cirrhosis and hepatic coma. Hepatology. 1991;14:1040-5.

Cohen CW, et al. A ketogenic diet reduces central obesity and serum insulin in women with ovarian or endometrial cancer. J Nutr. 2018;148:1253-60.

Coleman RL, et al. Secondary surgical cytoreduction for recurrent ovarian cancer. N Engl J Med. 2019;381:1929-39.

Cox G, Koteva K, Wright GD. An unusual class of anthracyclines potentiate Gram-positive antibiotics in intrinsically resistant Gram-negative bacteria. J Antimicrob Chemother. 2014;69:1844-55.

Curtarello M, et al. Rewiring of lipid metabolism and storage in ovarian cancer cells after Anti-VEGF therapy. Cells. 2019;8:E1601.

Curtin N, Szabo C. Therapeutic applications of parp inhibitors: anticancer therapy and beyond. Mol Aspects Med. 2013;6:1043-258.

Curtin NJ, Szabo C. Poly(ADP-ribose) polymerase inhibition: past, present and future. Nat Rev Drug Discov. 2020;19:711-36.

Curtin N, et al. Repositioning PARP inhibitors for SARS-CoV-2 infection(COVID-19); a new multi-pronged therapy for acute respiratory distress syndrome? Br J Pharmacol. 2020;177:3635-45.

Daoud SS, Forde NH. Synergistic cytotoxic actions of cisplatin and liposomal valinomycin on human ovarian carcinoma cells. Cancer Chemother Pharmacol. 1991;28:370-6.

Dedduwa-Mudalige GN, Chow CS. Cisplatin targeting of bacterial ribosomal RNA hairpins. Int J Mol Sci. 2015;16:21392-409.

Derosa L, et al. Gut Bacteria Composition Drives Primary Resistance to Cancer Immunotherapy in Renal Cell Carcinoma Patients. Eur Urol. 2020. https://doi.org/10.1016/j.eururo.2020.04.044.

Desiderio MA, et al. Treatment with inhibitors of polyamine biosynthesis, which selectively lower intracellular spermine, does not affect the activity of alkylating agents but antagonizes the cytotoxicity of DNA topoisomerase II inhibitors. Br J Cancer. 1997;75:1028-34.

Devaraj S, Hemarajata P, Versalovic J. The human gut microbiome and body metabolism: implications for obesity and diabetes. Clin Chem. 2013;59:617-28.

Dhakal D, et al. Complete genome sequence of Streptomyces peucetius ATCC 27952 , the producer of anticancer anthracyclines and diverse secondary metabolites. J Biotechnol. 2018;267:50-4.

Diani-Moore S, et al. Identification of the aryl hydrocarbon receptor target gene TiPARP as a mediator of suppression of hepatic gluconeogenesis by 2,3,7,8-tetrachlorodibenzo-p-dioxin and of nicotinamide as a corrective agent for this effect. J Biol Chem. 2010;285:38801-10.

Dood RL, et al. Defining survivorship trajectories across patients with solid tumors: an evidence-based approach. JAMA Oncol. 2018:4:1519-26.

Edwardson DW, et al. Inflammatory cytokine production in tumor cells upon chemotherapy drug exposure or upon selection for drug resistance. PLOS ONE. 2017;12:e0183662.

El Aidy S, Kunze W, Bienenstock J, Kleerebezem M. The microbiota and the gutbrain axis: insights from the temporal and spatial mucosal alterations during colonisation of the germfree mouse intestine. Benef Microbes. 2012:3:251-9.

El Alam MB, et al. Adaptive changes in the gut microbiome during standardof-care chemoradiotherapy for gynecologic cancers. bioRxiv. 2020. https://doi.org/10.1101/2020.04.10.036426.

Elkrief A, Derosa L, Kroemer G, Zitvogel L, Routy B. The negative impact of antibiotics on outcomes in cancer patients treated with immunotherapy: a new independent prognostic factor? Ann Oncol. 2019;30:1572-9.

Encarnação JC, et al. Butyrate, a dietary fiber derivative that improves irinotecan effect in colon cancer cells. J Nutr Biochem. 2018;56:183-92.

Ervin SM, et al. Gut microbial beta-glucuronidases reactivate estrogens as components of the estrobolome that reactivate estrogens. J Biol Chem. 2019;294:18586-99.

Estrella VC, et al. Lysophosphatidic acid induction of urokinase plasminogen activator secretion requires activation of the p38MAPK pathway. Int J Oncol. 2007:31:441-9.

Fachi JL, et al. Acetate coordinates neutrophil and ILC3 responses against $C$. difficile through FFAR2. J Exp Med. 2020;217(3):133544.

Fagotti A, et al. Phase III randomised clinical trial comparing primary surgery versus neoadjuvant chemotherapy in advanced epithelial ovarian 
cancer with high tumour load (SCORPION trial): Final analysis of perioperative outcome. Eur J Cancer. 2016;59:22-33.

Fan $L$, et al. Identification of metabolic biomarkers to diagnose epithelial ovarian cancer using a UPLC/QTOF/MS platform. Acta Oncol. 2012;51:473-9.

Fan $L$, et al. Use of plasma metabolomics to identify diagnostic biomarkers for early stage epithelial ovarian cancer. J Cancer. 2016;7:1265-72.

Fellows R, Varga-Weisz P. Chromatin dynamics and histone modifications in intestinal microbiota-host crosstalk. Mol Metab. 2020;38:100925.

Finlay BB, et al. Can we harness the microbiota to enhance the efficacy of cancer immunotherapy? Nat Rev Immunol. 2020. https://doi.org/10. 1038/s41577-020-0374-6.

Flores R, et al. Fecal microbial determinants of fecal and systemic estrogens and estrogen metabolites: a cross-sectional study. J Transl Med. 2012;10:253.

Fong MY, McDunn J, Kakar SS. Identification of metabolites in the normal ovary and their transformation in primary and metastatic ovarian cancer. PLOS ONE. 2011;6:e19963.

Friedman GD, et al. Antibiotics and risk of breast cancer: up to 9 years of follow-up of 2.1 million women. Cancer Epidemiol Biomarkers Prev. 2006;15:2102-6.

Gajdács M, Spengler G. The role of drug repurposing in the development of novel antimicrobial drugs: non-antibiotic pharmacological agents as quorum sensing-inhibitors. Antibiotics. 2019. https://doi.org/10.3390/ antibiotics8040270.

Gao J, et al. Impact of the gut microbiota on intestinal immunity mediated by tryptophan metabolism. Front Cell Infect Microbiol. 2018. https://doi. org/10.3389/fcimb.2018.00013.

Garcia-Quintanilla M, Prieto Al, Barnes L, Ramos-Morales F, Casadesus J. Bileinduced curing of the virulence plasmid in Salmonella enterica serovar Typhimurium. J Bacteriol. 2006;188:7963-5.

Ge J, Kang J, Ping W. Effect of acetic acid on bacteriocin production by grampositive bacteria. J Microbiol Biotechnol. 2019;29:1341-8.

Gerard P. Metabolism of cholesterol and bile acids by the gut microbiota. Pathogens. 2013;3:14-24.

Glezerman $M$, et al. Tumor necrosis factor-alpha and interleukin-6 are differently expressed by fresh human cancerous ovarian tissue and primary cell lines. Eur Cytokine Netw. 1998;9:171-9.

Gopalakrishnan V, et al. Gut microbiome modulates response to anti-PD-1 immunotherapy in melanoma patients. Science. 2018;359:97-103.

Gupta D, et al. Expanding the roles for pregnane X receptor in cancer: proliferation and drug resistance in ovarian cancer. Clin Cancer Res. 2008:14:5332-40.

Hall A, Versalovic J. Microbial metabolism in the mammalian gut: molecular mechanisms and clinical implications. J Pediatr Gastroenterol Nutr. 2018;66:S72-9.

Han X, Wilbanks GD, Devaja O, Ruperelia V, Raju KS. IL-2 enhances standard IFNgamma/LPS activation of macrophage cytotoxicity to human ovarian carcinoma in vitro: a potential for adoptive cellular immunotherapy. Gynecol Oncol. 1999;75:198-210.

Hanahan D, Weinberg RA. The hallmarks of cancer. Cell. 2000;100:57-70.

Hanahan D, Weinberg RA. Hallmarks of cancer: the next generation. Cell. 2011;144:646-74.

Hayase R, Eguchi K, Sekiba K. Polyamine levels in gynecologic malignancies. Acta Med Okayama. 1985;39:35-45.

Hector S, et al. Polyamine catabolism in platinum drug action: Interactions between oxaliplatin and the polyamine analogue N1, N11-diethylnorspermine at the level of spermidine/spermine $\mathrm{N} 1$-acetyltransferase. Mol Cancer Ther. 2004;3:813-22.

Hedenborg G, Jönsson G, Norman A, Wisén O. Bile constituents in ascitic fluid. Scand J Clin Lab Invest. 1988;48:543-52.

Heintz AP, et al. Carcinoma of the ovary. J Epidemiol Biostat. 2001;6:107-38.

Hilvo $\mathrm{M}$, et al. Accumulated metabolites of hydroxybutyric acid serve as diagnostic and prognostic biomarkers of ovarian high-grade serous carcinomas. Cancer Res. 2016;76:796-804.

Horowitz NS, et al. Novel cytotoxic agents from an unexpected source: bile acids and ovarian tumor apoptosis. Gynecol Oncol. 2007:107:344-9.

Huang JM, et al. Atractylenolide-I sensitizes human ovarian cancer cells to paclitaxel by blocking activation of TLR4/MyD88-dependent pathway. Sci Rep. 2014;4:3840.
Huang $\mathrm{HC}$, et al. Mechanism-informed repurposing of minocycline overcomes resistance to topoisomerase inhibition for peritoneal carcinomatosis. Mol Cancer Ther. 2018;17:508-20.

Huleihel $M$, et al. Distinct patterns of expression of interleukin-1 alpha and beta by normal and cancerous human ovarian tissues. Eur Cytokine Netw. 1997;8:179-87.

Hummell NA, Kirienko NV. Repurposing bioactive compounds for treating multidrug-resistant pathogens. J Med Microbiol. 2020;69:881-94.

Hurst JH, Hooks SB. Lysophosphatidic acid stimulates cell growth by different mechanisms in SKOV-3 and Caov-3 ovarian cancer cells: distinct roles for Gi- and Rho-dependent pathways. Pharmacology. 2009;83:333-47.

Idahl A, et al. Chlamydia trachomatis and Mycoplasma genitalium plasma antibodies in relation to epithelial ovarian tumors. Infect Dis Obstet Gynecol. 2011;2011:824627.

Inaba T, Obana N, Habe H, Nomura N. Biofilm formation by streptococcus mutans is enhanced by indole via the quorum sensing pathway. Microb Environ. 2020;35:Me19164.

Ingman WV. The gut microbiome: a new player in breast cancer metastasis. Cancer Res. 2019;79:3539-41.

Innao V, Allegra AG, Musolino C, Allegra A. New frontiers about the role of human microbiota in immunotherapy: the immune checkpoint inhibitors and CART-cell therapy era. Int J Mol Sci. 2020. https://doi.org/10. 3390/ijms21238902.

Irinotecan. Drugs and lactation database (LactMed). Bethesda: National Library of Medicine (US); 2006.

Jaaback K, Johnson N. Intraperitoneal chemotherapy for the initial management of primary epithelial ovarian cancer. Cochrane Database Syst Rev. 2006. https://doi.org/10.1002/14651858.CD005340.pub2.

Jakobsdottir G, Bjerregaard JH, Skovbjerg H, Nyman M. Fasting serum concentration of short-chain fatty acids in subjects with microscopic colitis and celiac disease: no difference compared with controls, but between genders. Scand J Gastroenterol. 2013;48:696-701.

Jayson GC, Kohn EC, Kitchener HC, Ledermann JA. Ovarian cancer. Lancet. 2014;384:1376-88.

Jeong KJ, et al. The Rho/ROCK pathway for lysophosphatidic acid-induced proteolytic enzyme expression and ovarian cancer cell invasion. Oncogene. 2012;31:4279-89.

Jeong GO, et al. TAZ mediates lysophosphatidic acid-induced migration and proliferation of epithelial ovarian cancer cells. Cell Physiol Biochem. 2013;32:253-63.

Jezierska-Drutel A, Rosenzweig SA, Neumann CA. Role of oxidative stress and the microenvironment in breast cancer development and progression. Adv Cancer Res. 2013;119:107-25.

Jin UH, et al. Short chain fatty acids enhance aryl hydrocarbon (Ah) responsiveness in mouse colonocytes and caco-2 human colon cancer cells. Sci Rep. 2017;7:10163.

Jin Q, Noel O, Nguyen M, Sam L, Gerhard GS. Bile acids upregulate BRCA1 and downregulate estrogen receptor 1 gene expression in ovarian cancer cells. ECP. 2018;27:553-6.

Juhász J, Bihary D, Jády A, Pongor S, Ligeti B. Differential signal sensitivities can contribute to the stability of multispecies bacterial communities. Biol Direct. 2017;12:22.

Kandell RL, Bernstein C. Bile salt/acid induction of DNA damage in bacterial and mammalian cells: implications for colon cancer. Nutr Cancer. 1991;16:227-38.

Kaplan F, Teksen F. Apoptotic effects of salinomycin on human ovarian cancer cell line (OVCAR-3). Tumour Biol. 2016;37:3897-903.

Kashani B, et al. Small molecule inhibitor of TLR4 inhibits ovarian cancer cell proliferation: new insight into the anticancer effect of TAK-242 (Resatorvid). Cancer Chemother Pharmacol. 2020;85:47-59.

Katsumata $\mathrm{N}$, et al. Dose-dense paclitaxel once a week in combination with carboplatin every 3 weeks for advanced ovarian cancer: a phase 3, open-label, randomised controlled trial. Lancet. 2009;374:1331-8.

$\mathrm{Ke} \mathrm{C}$, et al. Large-scale profiling of metabolic dysregulation in ovarian cancer. Int J Cancer. 2015;136:516-26.

Kelly MG, et al. TLR-4 signaling promotes tumor growth and paclitaxel chemoresistance in ovarian cancer. Cancer Res. 2006;66:3859-68.

Kershaw $\mathrm{MH}$, et al. A phase I study on adoptive immunotherapy using genemodified T cells for ovarian cancer. Clin Cancer Res . 2006;12:6106-15.

Kim CH. Immune regulation by microbiome metabolites. Immunology. 2018;154:220-9. 
Kim SI, et al. Metagenomic analysis of serum microbe-derived extracellular vesicles and diagnostic models to differentiate ovarian cancer and benign ovarian tumor. Cancers (Basel). 2020;12:E1309.

Kindelberger DW, et al. Intraepithelial carcinoma of the fimbria and pelvic serous carcinoma: evidence for a causal relationship. Am J Surg Pathol. 2007;31:161-9.

Kirkup B, et al. Perturbation of the gut microbiota by antibiotics results in accelerated breast tumour growth and metabolic dysregulation. BioRxiv. 2019. https://doi.org/10.1101/553602.

Kirkup BM, et al. Antibiotic-induced disturbances of the gut microbiota result in accelerated breast tumour growth via a mast cell-dependent pathway. bioRxiv. 2020. https://doi.org/10.1101/2020.1103.1107.982108.

Kiss B, et al. Oncobiosis and microbial metabolite signaling in pancreatic adenocarcinoma. Cancers (Basel). 2020;12:E1068.

Kloskowski T, Olkowska J, Nazlica A, Drewa T. The influence of ciprofloxacin on hamster ovarian cancer cell line CHO AA8. Acta Pol Pharm. 2010;67:345-9.

Kojima M, et al. Sensitisation of human ovarian carcinoma cells to cis-diamminedichloroplatinum (II) by amphotericin B in vitro and in vivo. Eur J Cancer. 1994:30a:773-8.

Kovács P, et al. Lithocholic acid, a metabolite of the microbiome, increases oxidative stress in breast cancer. Cancers (Basel). 2019. https://doi.org/ 10.3390/cancers11091255.

Kovács T, et al. Cadaverine, a metabolite of the microbiome, reduces breast cancer aggressiveness through trace amino acid receptors. Sci Rep. 2019;9:1300.

Kovacs T, Miko E, Ujlaki G, Sari Z, Bai P. The microbiome as a component of the tumor microenvironment. Adv Exp Med Biol. 2020;1225:137-53.

Krupitza G, et al. Sodium butyrate inhibits c-myc splicing and interferes with signal transduction in ovarian carcinoma cells. Carcinogenesis. 1995;16:1199-205.

Krupitza G, et al. Genes related to growth and invasiveness are repressed by sodium butyrate in ovarian carcinoma cells. Br J Cancer. 1996;73:433-8.

Ktsoyan ZA, et al. Systemic concentrations of short chain fatty acids are elevated in salmonellosis and exacerbation of familial mediterranean fever. Front Microbiol. 2016;7:776.

Kuo WT, Lee TC, Yu LC. Eritoran suppresses colon cancer by altering a functional balance in toll-like receptors that bind lipopolysaccharide. Cancer Res. 2016;76:4684-95.

Kurman RJ. Origin and molecular pathogenesis of ovarian high-grade serous carcinoma. Ann Oncol. 2013;24(Suppl 10):x16-21.

Kurman RJ, Shih IM. Molecular pathogenesis and extraovarian origin of epithelial ovarian cancer-shifting the paradigm. Hum Pathol. 2011;42:918-31.

Kyrgiou M, Salanti G, Pavlidis N, Paraskevaidis E, loannidis JP. Survival benefits with diverse chemotherapy regimens for ovarian cancer: meta-analysis of multiple treatments. J Natl Cancer Inst. 2006;98:1655-63.

Kyriakides M, et al. Metabonomic analysis of ovarian tumour cyst fluid by proton nuclear magnetic resonance spectroscopy. Oncotarget. 2016;7:7216-26.

Lamas B, et al. CARD9 impacts colitis by altering gut microbiota metabolism of tryptophan into aryl hydrocarbon receptor ligands. Nat Med. 2016;22:598-605.

Lamb R, et al. Antibiotics that target mitochondria effectively eradicate cancer stem cells, across multiple tumor types: treating cancer like an infectious disease. Oncotarget. 2015;6:4569-84.

Langdon SP, et al. Effect of sodium butyrate and other differentiation inducers on poorly differentiated human ovarian adenocarcinoma cell lines. Cancer Res. 1988;48:6161-5.

Łaniewski P, Ilhan ZE, Herbst-Kralovetz MM. The microbiome and gynaecological cancer development, prevention and therapy. Nat Rev Urol. 2020;17:232-50.

Larmonier CB, et al. Transcriptional reprogramming and resistance to colonic mucosal injury in poly(ADP-ribose) polymerase 1 (PARP1)-deficient mice. J Biol Chem. 2016;291:8918-30.

Larsen HM, et al. Clinical evaluation and treatment of chronic bowel symptoms following cancer in the colon and pelvic organs. Acta Oncol. 2019;58:776-81.

Lau A, Villeneuve NF, Sun Z, Wong PK, Zhang DD. Dual roles of Nrf2 in cancer. Pharmacol Res. 2008;58:262-70.
Lawton F, Griffin M, Slack J, Blackledge G. Urinary polyamine excretion patterns in patients with epithelial ovarian cancer. Gynecol Obstet Invest. 1989:28:212-4

Ledermann J, et al. Olaparib maintenance therapy in platinum-sensitive relapsed ovarian cancer. N Engl J Med. 2012;366:1382-92.

Lee $Z$, et al. Lysophosphatidic acid is a major regulator of growth-regulated oncogene alpha in ovarian cancer. Cancer Res. 2006;66:2740-8.

Lee HG, et al. Salinomycin reduces stemness and induces apoptosis on human ovarian cancer stem cell. J Gynecol Oncol. 2017;28:e14

Lee YJ, Li KY, Wang PJ, Huang HW, Chen MJ. Alleviating chronic kidney disease progression through modulating the critical genus of gut microbiota in a cisplatin-induced Lanyu pig model. J Food Drug Anal. 2020:28:103-14.

Lee TH, et al. Lactobacillus salivarius BP121 prevents cisplatin-induced acute kidney injury by inhibition of uremic toxins such as indoxyl sulfate and p-cresol sulfate via alleviating dysbiosis. Int J Mol Med. 2020;45:1130-40.

Leitzmann MF, et al. Body mass index and risk of ovarian cancer. Cancer. 2009;115:812-22.

Levinson KL, et al. Gynecologic cancer in HIV-infected women: treatment and outcomes in a multi-institutional cohort. AIDS (London, England). 2018;32:171-7.

Li R, et al. Salinomycin repressed the epithelial-mesenchymal transition of epithelial ovarian cancer cells via downregulating Wnt/ $\beta$-catenin pathway. Onco Targets Ther. 2017;10:1317-25.

Li Q, Ren Y, Fu X. Inter-kingdom signaling between gut microbiota and their host. Cell Mol Life Sci. 2019:76:2383-9.

Li S, Fei X, Chi Y, Cao L. Impact of the acetate/oleic acid ratio on the performance, quorum sensing, and microbial community of sequencing batch reactor system. Biores Technol. 2020;296:122279.

Liaudet $L$, et al. The flagellin-TLR5 axis: therapeutic opportunities. Drug News Perspect. 2002;15:397-409.

Lin M-E, Herr DR, Chun J. Lysophosphatidic acid (LPA) receptors: signaling properties and disease relevance. Prostaglandins Other Lipid Mediat. 2010:91:130-8.

Lin XB, et al. Irinotecan (CPT-11) chemotherapy alters intestinal microbiota in tumour bearing rats. PLOS ONE. 2012;7:e39764.

Lin $X B$, et al. The role of intestinal microbiota in development of irinotecan toxicity and in toxicity reduction through dietary fibres in rats. PLOS ONE. 2014;9:e83644.

Lin R, Liu W, Piao M, Zhu H. A review of the relationship between the gut microbiota and amino acid metabolism. Amino Acids. 2017:49:2083-90.

Lu Y-C, Yeh W-C, Ohashi PS. LPS/TLR4 signal transduction pathway. Cytokine. 2008:42:145-51.

Lynch HT, Watson P, Lynch JF, Conway TA, Fili M. Hereditary ovarian cancer Heterogeneity in age at onset. Cancer. 1993;71:573-81.

Macpherson L, et al. 2,3,7,8-Tetrachlorodibenzo-p-dioxin poly(ADP-ribose) polymerase (TiPARP, ARTD14) is a mono-ADP-ribosyltransferase and repressor of aryl hydrocarbon receptor transactivation. Nucleic Acids Res. 2013;41:1604-21.

Madeo F, et al. Nutritional aspects of spermidine. Annu Rev Nutr. 2020;40:135-59.

Magnusdottir S, Thiele I. Modeling metabolism of the human gut microbiome. Curr Opin Biotechnol. 2017;51:90-6.

MahmoudianDehkordi S, et al. Altered bile acid profile associates with cognitive impairment in Alzheimer's disease-an emerging role for gut microbiome. Alzheimers Dement. 2019;15:76-92.

Mardinoglu A, et al. The gut microbiota modulates host amino acid and glutathione metabolism in mice. Mol Syst Biol. 2015;11:834.

Marshall WJ, Lapsley M, Day A. Clinical Chemistry. 8th ed. Amsterdam: Elsevier; 2016.

Marverti G, et al. Modulation of cis-diamminedichloroplatinum (II) accumulation and cytotoxicity by spermine in sensitive and resistant human ovarian carcinoma cells. Eur J Cancer. 1997;33:669-75.

Marverti G, et al. Differential induction of spermidine/spermine N1-acetyltransferase activity in cisplatin-sensitive and -resistant ovarian cancer cells in response to N1, N12-bis(ethyl)spermine involves transcriptional and post-transcriptional regulation. Eur J Cancer. 2001;37:281-9.

Marverti $\mathrm{G}$, et al. Cisplatin-resistance modulates the effect of protein synthesis inhibitors on spermidine/spermine N(1)-acetyltransferase expression. Int J Biochem Cell Biol. 2004:36:123-37. 
Marverti G, et al. Spermidine/spermine N1-acetyltransferase transient overexpression restores sensitivity of resistant human ovarian cancer cells to N1, N12-bis(ethyl)spermine and to cisplatin. Carcinogenesis. 2005;26:1677-86.

Masuyama H, Nakamura K, Nobumoto E, Hiramatsu Y. Inhibition of pregnane $X$ receptor pathway contributes to the cell growth inhibition and apoptosis of anticancer agents in ovarian cancer cells. Int J Oncol. 2016;49:1211-20.

Mateo J, et al. A decade of clinical development of PARP inhibitors in perspective. Ann Oncol. 2019;30:1437-47.

Matson $\mathrm{V}$, et al. The commensal microbiome is associated with anti-PD-1 efficacy in metastatic melanoma patients. Science. 2018;359:104-8.

McCarron AJ, et al. Antibacterial effects on acinetobacter species of commonly employed antineoplastic agents used in the treatment of haematological malignancies: an in vitro laboratory evaluation. Br J Biomed Sci. 2012;69:14-7.

Medeiros F, et al. The tubal fimbria is a preferred site for early adenocarcinoma in women with familial ovarian cancer syndrome. Am J Surg Pathol. 2006;30:230-6.

Medina-Franco H, Cortés-González R, Lambreton-Hinojosa F, FimbresMorales A, Vargas-Siordia JC. Neoadjuvant chemotherapy increases R0 cytoreduction rate but does not improve final outcome in advanced epithelial ovarian cancer. Ann Surg Oncol. 2017;24:1330-5.

Mendoza L. Potential effect of probiotics in the treatment of breast cancer. Oncol Rev. 2019;13:422.

Menzies KJ, Zhang H, Katsyuba E, Auwerx J. Protein acetylation in metabolism - metabolites and cofactors. Nat Rev Endocrinol. 2016;12:43-60.

Merritt ME, Donaldson JR. Effect of bile salts on the DNA and membrane integrity of enteric bacteria. J Med Microbiol. 2009;58:1533-41.

Mert I, Walther-Antonio M, Mariani A. Case for a role of the microbiome in gynecologic cancers: clinician's perspective. J Obstet Gynaecol Res. 2018;44:1693-704.

Miao R, et al. Assessment of peritoneal microbial features and tumor marker levels as potential diagnostic tools for ovarian cancer. PLoS ONE. 2020;15:e0227707.

Michael AJ. Polyamine function in archaea and bacteria. J Biol Chem. 2018;293:18693-701.

Michalak M, Lach MS, Antoszczak M, Huczyński A, Suchorska WM. Overcoming resistance to platinum-based drugs in ovarian cancer by salinomycin and its derivatives-an in vitro study. Molecules. 2020. https://doi.org/10. 3390/molecules25030537.

Miko E, Vida A, Bai P. Translational aspects of the microbiome-to be exploited. Cell Biol Toxicol. 2016;32:153-6.

Miko E, et al. Lithocholic acid, a bacterial metabolite reduces breast cancer cell proliferation and aggressiveness. Biochim Biophys Acta. 2018;1859:958-74.

Miko E, et al. Microbiome-microbial metabolome-cancer cell interactions in breast cancer-familiar, but unexplored. Cells. 2019;8(4):E293.

Miller EA, Beasley DE, Dunn RR, Archie EA. Lactobacilli dominance and vaginal $\mathrm{pH}$ : why is the human vaginal microbiome unique? Front Microbiol. 2016;7:1936.

Mirza MR, et al. Niraparib maintenance therapy in platinum-sensitive, recurrent ovarian cancer. N Engl J Med. 2016:375:2154-64.

Miyake K, et al. Tumor-targeting Salmonella typhimurium A1-R overcomes nab-paclitaxel resistance in a cervical cancer PDOX mouse model. Arch Gynecol Obstet. 2019;299:1683-90.

Mori G, et al. Gut microbiota analysis in postoperative lynch syndrome patients. Front Microbiol. 2019;10:1746.

Morrison J, Haldar K, Kehoe S, Lawrie TA. Chemotherapy versus surgery for initial treatment in advanced ovarian epithelial cancer. Cochrane Database Syst Rev. 2012. https://doi.org/10.1002/14651858.CD005343.pub3.

Mrkvicova A, et al. The effect of sodium butyrate and cisplatin on expression of EMT markers. PLoS ONE. 2019;14:e0210889.

Muccioli M, Benencia F. Toll-like receptors in ovarian cancer as targets for immunotherapies. Front Immunol. 2014;5:341.

NCCN Guidelines [Internet]. https://www.nccn.org/professionals/physician_ gls/default.aspx.

Nené NR, et al. Association between the cervicovaginal microbiome, BRCA1 mutation status, and risk of ovarian cancer: a case-control study. Lancet Oncol. 2019;20:1171-82.
Ness RB, Goodman MT, Shen C, Brunham RC. Serologic evidence of past infection with Chlamydia trachomatis, in relation to ovarian cancer. J Infect Dis. 2003;187:1147-52.

Niemi RJ, et al. Urinary polyamines as biomarkers for ovarian cancer. Int J Gynecol Cancer. 2017;27:1360-6.

Ochi A, et al. MyD88 inhibition amplifies dendritic cell capacity to promote pancreatic carcinogenesis via Th2 cells. J Exp Med. 2012;209:1671-87.

Oelschlaeger TA, Tall BD. Invasion of cultured human epithelial cells by Klebsiella pneumoniae isolated from the urinary tract. Infect Immun. 1997;65:2950-8.

Osman AEG, Luke JJ. The impact of the fecal microbiome on cancer immunotherapy. BioDrugs. 2019;33:1-7.

Pagliari D, et al. Gut microbiota-immune system crosstalk and pancreatic disorders. Mediators Inflamm. 2018;2018:7946431.

Parajuli B, et al. Salinomycin inhibits Akt/NF-KB and induces apoptosis in cisplatin resistant ovarian cancer cells. Cancer Epidemiol. 2013a;37:512-7.

Parajuli B, et al. Salinomycin induces apoptosis via death receptor-5 upregulation in cisplatin-resistant ovarian cancer cells. Anticancer Res. 2013b;33:1457-62.

Parajuli P, Pandey RP, Nguyen THT, Dhakal D, Sohng JK. Substrate scope of o-methyltransferase from streptomyces peucetius for biosynthesis of diverse natural products methoxides. Appl Biochem Biotechnol. 2018;184:1404-20.

Park GB, Chung YH, Kim D. Induction of galectin-1 by TLR-dependent PI3K activation enhances epithelial-mesenchymal transition of metastatic ovarian cancer cells. Oncol Rep. 2017;37:3137-45.

Paschos GK, FitzGerald GA. Circadian clocks and metabolism: implications for microbiome and aging. Trends Genet. 2017;33:760-9.

Patel K, Craig SB, McBride MG, Palepu NR. Microbial inhibitory properties and stability of topotecan hydrochloride injection. AJHP . 1998;55:1584-7.

Pathak S, Wilczyński JR, Paradowska E. Factors in oncogenesis: viral infections in ovarian cancer. Cancers (Basel). 2020;12:E561.

Pedroso $S$, et al. Evaluation of mucositis induced by irinotecan after microbial colonization in germ-free mice. Microbiology. 2015;161:1950-60.

Perales-Puchalt A, et al. Frontline Science: Microbiota reconstitution restores intestinal integrity after cisplatin therapy. J Leukoc Biol. 2018;103:799-805.

Plewa S, et al. Usefulness of amino acid profiling in ovarian cancer screening with special emphasis on their role in cancerogenesis. Int J Mol Sci. 2017. https://doi.org/10.3390/ijms18122727.

Poore GD, et al. Microbiome analyses of blood and tissues suggest cancer diagnostic approach. Nature. 2020;579:567-74.

Pourgholami MH, Ataie-Kachoie P, Badar S, Morris DL. Minocycline inhibits malignant ascites of ovarian cancer through targeting multiple signaling pathways. Gynecol Oncol. 2013;129:113-9.

Poveda AM, et al. Bevacizumab combined with weekly paclitaxel, pegylated liposomal doxorubicin, or topotecan in platinum-resistant recurrent ovarian cancer: analysis by chemotherapy cohort of the randomized phase III AURELIA trial. J Clin Oncol. 2015;33:3836-8.

Prieto Al, Ramos-Morales F, Casadesus J. Bile-induced DNA damage in Salmonella enterica. Genetics. 2004;168:1787-94.

Prieto Al, Ramos-Morales F, Casadesus J. Repair of DNA damage induced by bile salts in Salmonella enterica. Genetics. 2006;174:575-84.

Pryde SE, Duncan SH, Hold GL, Stewart CS, Flint HJ. The microbiology of butyrate formation in the human colon. FEMS Microbiol Lett. 2002;217:133-9.

Pushalkar $\mathrm{S}$, et al. The pancreatic cancer microbiome promotes oncogenesis by induction of innate and adaptive immune suppression. Cancer Discov. 2018;8:403-16.

Pustilnik TB, et al. Lysophosphatidic acid induces urokinase secretion by ovarian cancer cells. Clin Cancer Res. 1999;5:3704-10.

Qiu J, et al. The aryl hydrocarbon receptor regulates gut immunity through modulation of innate lymphoid cells. Immunity. 2012;36:92-104.

Querleu D, et al. European Society of Gynaecological Oncology (ESGO) guidelines for ovarian cancer surgery. Int J Gynecol Cancer. 2017;27:1534-42.

Rahbar Saadat Y, et al. Modulatory role of vaginal-isolated lactococcus lactis on the expression of miR-21, miR-200b, and TLR-4 in CAOV-4 cells and in silico revalidation. Prob Antimicrob Proteins. 2019;12:1083-96.

Ramirez-Perez O, Cruz-Ramon V, Chinchilla-Lopez P, Mendez-Sanchez N. The role of the gut microbiota in bile acid metabolism. Ann Hepatol. 2017;16:s15-20. https://doi.org/10.5604/5601.3001.0010.5494. 
Ramos-Molina B, Queipo-Ortuño MI, Lambertos A, Tinahones FJ, Peñafiel R. Dietary and gut microbiota polyamines in obesity- and age-related diseases. Front Nutr. 2019;6:24.

Ranjbar S, Seyednejad SA, Azimi H, Rezaeizadeh H, Rahimi R. Emerging roles of probiotics in prevention and treatment of breast cancer: a comprehensive review of their therapeutic potential. Nutr Cancer. 2019;71:1-12.

Rasmussen CB, et al. Pelvic inflammatory disease and risk of invasive ovarian cancer and ovarian borderline tumors. Cancer Causes Control. 2013:24:1459-64.

Rasmussen $\mathrm{CB}$, et al. Pelvic inflammatory disease and the risk of ovarian cancer and borderline ovarian tumors: a pooled analysis of 13 case-control studies. Am J Epidemiol. 2017;185:8-20.

Rattanaphan P, Mittraparp-Arthorn P, Srinoun K, Vuddhakul V, Tansila N. Indole signaling decreases biofilm formation and related virulence of Listeria monocytogenes. FEMS microbial lett. 2020. https://doi.org/10.1093/ femsle/fnaa116.

Ravnik Z, Muthiah I, Dhanaraj P. Computational studies on bacterial secondary metabolites against breast cancer. J Biomol Struct Dyn. 2020. https:// doi.org/10.1080/07391102.2020.1805361.

Ray-Coquard I, et al. Olaparib plus bevacizumab as first-line maintenance in ovarian cancer. N Engl J Med. 2019;381:2416-28.

Ren Z, et al. Gut microbial profile analysis by MiSeq sequencing of pancreatic carcinoma patients in China. Oncotarget. 2017;8:95176-91.

Ribeiro RA, et al. Irinotecan- and 5-fluorouracil-induced intestinal mucositis: insights into pathogenesis and therapeutic perspectives. Cancer Chemother Pharmacol. 2016;78:881-93.

Ridlon JM, Bajaj JS. The human gut sterolbiome: bile acid-microbiome endocrine aspects and therapeutics. Acta Pharm Sin B. 2015;5:99-105.

Ridlon JM, Kang DJ, Hylemon PB. Bile salt biotransformations by human intestinal bacteria. J Lipid Res. 2006;47:241-59.

Risch HA, et al. Population BRCA1 and BRCA2 mutation frequencies and cancer penetrances: a kin-cohort study in Ontario, Canada. J Natl Cancer Inst. 2006;98:1694-706.

Roberts AB, Wallace BD, Venkatesh MK, Mani S, Redinbo MR. Molecular insights into microbial $\beta$-glucuronidase inhibition to abrogate CPT-11 toxicity. Mol Pharmacol. 2013;84:208-17.

Robinson KM, Crabtree J, Mattick JS, Anderson KE, Dunning Hotopp JC. Distinguishing potential bacteria-tumor associations from contamination in a secondary data analysis of public cancer genome sequence data. Microbiome. 2017. https://doi.org/10.1186/s40168-40016-40224-40168.

Rosenberg SA, Restifo NP, Yang JC, Morgan RA, Dudley ME. Adoptive cell transfer: a clinical path to effective cancer immunotherapy. Nat Rev Cancer. 2008;8:299-308

Rossi T, et al. Microbiota-derived metabolites in tumor progression and metastasis. Int J Mol Sci. 2020;21:E5786

Rough JJ, Monroy MA, Yerrum S, Daly JM. Anti-proliferative effect of LXR agonist T0901317 in ovarian carcinoma cells. J Ovarian Res. 2010:3:13.

Routy B, et al. Gut microbiome influences efficacy of PD-1-based immunotherapy against epithelial tumors. Science. 2018a;359:91-7.

Routy $B$, et al. The gut microbiota influences anticancer immunosurveillance and general health. Nat Rev Clin Oncol. 2018b;15:382-96.

Roy S, Trinchieri G. Microbiota: a key orchestrator of cancer therapy. Nat Rev Cancer. 2017:17:271-85.

Rutkowski MR, et al. Microbially driven TLR5-dependent signaling governs distal malignant progression through tumor-promoting inflammation. Cancer Cell. 2015;27:27-40.

Saffrey MJ. Aging of the mammalian gastrointestinal tract: a complex organ system. Age (Dordr). 2014;36:9603.

Sajadpoor Z, et al. Valproic acid promotes apoptosis and cisplatin sensitivity through downregulation of $\mathrm{H} 19$ noncoding RNA in ovarian A2780 Cells. Appl Biochem Biotechnol. 2018;185:1132-44.

Sári Z, et al. Fecal expression of E. coli lysine decarboxylase (LdcC) is downregulated in E-cadherin negative lobular breast carcinoma. Physiol Int. 2020. https://doi.org/10.1556/2060.2020.00016.

Sári Z, et al. Indolepropionic acid, a metabolite of the microbiome, has cytostatic properties in breast cancer by activating AHR and PXR receptors and inducing oxidative stress. Cancers (Basel). 2020a;12:E2411.

Sári Z, et al. Indoxylsulfate, a metabolite of the microbiome has cytostatic effects in breast cancer via activation of ahr and pxr receptors and induction of oxidative stress. Cancers (Basel). 2020b;12:E2915.
Sarin SK, Pande A, Schnabl B. Microbiome as a therapeutic target in alcoholrelated liver disease. J Hepatol. 2019;70:260-72.

Schaffler $\mathrm{H}$, Breitruck A. Clostridium difficile-from colonization to infection. Front Microbiol. 2018. https://doi.org/10.3389/fmicb.2018.00646.

Schepisi G, et al. Immunotherapy and its development for gynecological (ovarian, endometrial and cervical) tumors: from immune checkpoint inhibitors to Chimeric Antigen Receptor (CAR)-T cell therapy. Cancers (Basel). 2021. https://doi.org/10.3390/cancers13040840.

Schuldes $\mathrm{H}$, et al. Reversal of multidrug resistance and increase in plasma membrane fluidity in $\mathrm{CHO}$ cells with R-verapamil and bile salts. Eur J Cancer. 2001:37:660-7.

Schulz MD, et al. High-fat-diet-mediated dysbiosis promotes intestinal carcinogenesis independently of obesity. Nature. 2014;514:508-12.

Scoles DR, et al. Liver $X$ receptor agonist inhibits proliferation of ovarian carcinoma cells stimulated by oxidized low density lipoprotein. Gynecol Oncol. 2010;116:109-16.

Sengupta S, Xiao YJ, Xu Y. A novel laminin-induced LPA autocrine loop in the migration of ovarian cancer cells. Faseb j. 2003;17:1570-2.

Seo SS, et al. Combined effect of diet and cervical microbiome on the risk of cervical intraepithelial neoplasia. Clin Nutr. 2016;35:1434-41.

Sethi $V$, et al. Gut microbiota promotes tumor growth in mice by modulating immune response. Gastroenterology. 2018;155:33-7.

Shanmughapriya S, et al. Viral and bacterial aetiologies of epithelial ovarian cancer. Eur J Clin Microbiol Infect Dis. 2012:31:2311-7.

Shellman Z, et al. Bile acids: a potential role in the pathogenesis of pharyngeal malignancy. Clin Otolaryngol. 2017:42:969-73.

Shi LZ, et al. The aryl hydrocarbon receptor is required for optimal resistance to Listeria monocytogenes infection in mice. J Immunol. 2007;179:6952-62.

Shih le M, Kurman RJ. Ovarian tumorigenesis: a proposed model based on morphological and molecular genetic analysis. Am J Pathol. 2004;164:1511-8.

Shimazu T, et al. Suppression of oxidative stress by beta-hydroxybutyrate, an endogenous histone deacetylase inhibitor. Science. 2013;339:211-4.

Shu XO, Gao YT, Yuan JM, Ziegler RG, Brinton LA. Dietary factors and epithelial ovarian cancer. Br J Cancer. 1989:59:92-6.

Singh $\mathrm{H}$, et al. Gastro-intestinal and oral microbiome signatures associated with healthy aging. Geroscience. 2019. https://doi.org/10.1007/ s11357-11019-00098-11358.

Sipe LM, Chaib M, Pingili AK, Pierre JF, Makowski L. Microbiome, bile acids, and obesity: how microbially modified metabolites shape anti-tumor immunity. Immunol Rev. 2020:295:220-39.

Sittipo P, Shim JW, Lee YK. Microbial metabolites determine host health and the status of some diseases. Int J Mol Sci. 2019;20:E5296.

Sivan A, et al. Commensal Bifidobacterium promotes antitumor immunity and facilitates anti-PD-L1 efficacy. Science. 2015;350:1084-9.

Slocum MM, Sittig KM, Specian RD, Deitch EA. Absence of intestinal bile promotes bacterial translocation. Am Surg. 1992;58:305-10.

Smolková K, et al. NRF2 in regulating cancer metabolism. Antioxid Redox Signal. 2020;33:966-97.

Sonner JK, et al. Dietary tryptophan links encephalogenicity of autoreactive T cells with gut microbial ecology. Nat Commun. 2019;10:4877.

Sorg JA, Sonenshein AL. Inhibiting the initiation of Clostridium difficile spore germination using analogs of chenodeoxycholic acid, a bile acid. J Bacteriol. 2010;192:4983-90.

Stark D, et al. Standard chemotherapy with or without bevacizumab in advanced ovarian cancer: quality-of-life outcomes from the International Collaboration on Ovarian Neoplasms (ICON7) phase 3 randomised trial. Lancet Oncol. 2013;14:236-43.

Stuart GC, et al. 2010 Gynecologic Cancer InterGroup (GCIG) consensus statement on clinical trials in ovarian cancer: report from the Fourth Ovarian Cancer Consensus Conference. Int J Gynecol Cancer. 2011;21:750-5.

Sun T, Nguyen A, Gommerman JL. Dendritic cell subsets in intestinal immunity and inflammation. J Immunol. 2020;204:1075-83.

Sweet MJ, Hume DA. Bacterial lipopolysaccharide confers resistance to G418, doxorubicin, and taxol in the murine macrophage cell line, RAW264. J Leukoc Biol. 1996;59:280-6.

Szajnik M, et al. TLR4 signaling induced by lipopolysaccharide or paclitaxel regulates tumor survival and chemoresistance in ovarian cancer. Oncogene. 2009;28:4353-63. 
Tan J, Song M, Zhou M, Hu Y. Antibiotic tigecycline enhances cisplatin activity against human hepatocellular carcinoma through inducing mitochondrial dysfunction and oxidative damage. Biochem Biophys Res Commun. 2017:483:17-23.

Tang W, et al. Liver- and microbiome-derived bile acids accumulate in human breast tumors and inhibit growth and improve patient survival. Clin Cancer Res. 2019;11:1078-432.

Terao Y, et al. Sodium butyrate induces growth arrest and senescence-like phenotypes in gynecologic cancer cells. Int J Cancer. 2001;94:257-67.

Tewari KS, et al. Final overall survival of a randomized trial of bevacizumab for primary treatment of ovarian cancer. J Clin Oncol. 2019;37:2317-28.

Thomas RM, et al. Intestinal microbiota enhances pancreatic carcinogenesis in preclinical models. Carcinogenesis. 2018;39:1068-78.

Ticinesi A, et al. Exercise and immune system as modulators of intestinal microbiome: implications for the gut-muscle axis hypothesis. Exerc Immunol Rev. 2019;25:84-95.

Tofalo R, Cocchi S, Suzzi G. Polyamines and gut microbiota. Front Nutr. 2019;6:16.

Torre LA, et al. Global cancer statistics, 2012. CA Cancer J Clin. 2015;65:87-108.

Trabert B, et al. Antibodies against chlamydia trachomatis and ovarian cancer risk in two independent populations. J Natl Cancer Inst. 2019;111:129-36.

Trenti A, et al. Effects of digitoxin on cell migration in ovarian cancer inflammatory microenvironment. Biochem Pharmacol. 2018;154:414-23.

Tsuei J, Chau T, Mills D, Wan YJ. Bile acid dysregulation, gut dysbiosis, and gastrointestinal cancer. Exp Biol Med (Maywood). 2014;239:1489-504.

Turkoglu $\mathrm{O}$, et al. Metabolomics of biomarker discovery in ovarian cancer: a systematic review of the current literature. Metabolomics. 2016. https:// doi.org/10.1007/s11306-016-0990-0.

Venkatesh M, et al. Symbiotic bacterial metabolites regulate gastrointestinal barrier function via the xenobiotic sensor PXR and Toll-like receptor 4. Immunity. 2014;41:296-310.

Vergara D, et al. The cancer microbiota: EMT and inflammation as shared molecular mechanisms associated with plasticity and progression. J Oncol. 2019. https://doi.org/10.1155/2019/1253727.

Vergote I, et al. Neoadjuvant chemotherapy or primary surgery in stage IIIC or IV ovarian cancer. N Engl J Med. 2010;363:943-53.

Vetizou M, et al. Anticancer immunotherapy by CTLA-4 blockade relies on the gut microbiota. Science. 2015;350:1079-84.

Viaud $\mathrm{S}$, et al. Harnessing the intestinal microbiome for optimal therapeutic immunomodulation. Cancer Res. 2014;74:4217-21.

Vida A, Kardos G, Kovacs T, Bodrogi BL, Bai P. Deletion of poly(ADPribose) polymerase-1 changes the composition of the microbiome in the gut. Mol Med Rep. 2018;18:4335-41.

Vida A, Bodrogi BL, Balogh B, Bai P. Taxamat: automated biodiversity data management tool—implications for microbiome studies. Physiol Int. 2020. https://doi.org/10.1556/2060.2020.00004.

Vindevogel $\mathrm{E}$, et al. The use of toll-like receptor 4 agonist to reshape the immune signature in ovarian cancer. Anticancer Res. 2016;36:5781-92.

Vyas $V$, et al. Synchronous occurrence of brucellosis and ovarian cancer: a case report. AJC . 2007;6:257-9.

Wallace BD, et al. Structure and inhibition of microbiome $\beta$-glucuronidases essential to the alleviation of cancer drug toxicity. Chem Biol. 2015;22:1238-49.

Wanderley $\mathrm{CW}$, et al. Paclitaxel reduces tumor growth by reprogramming tumor-associated macrophages to an M1 profile in a TLR4-dependent manner. Cancer Res. 2018;78:5891-900.

Wang Y, Masuyama H, Nobumoto E, Zhang G, Hiramatsu Y. The inhibition of constitutive androstane receptor-mediated pathway enhances the effects of anticancer agents in ovarian cancer cells. Biochem Pharmacol. 2014;90:356-66.

Wang AC, et al. TLR4 induces tumor growth and inhibits paclitaxel activity in MyD88-positive human ovarian carcinoma in vitro. Oncol Lett. 2014;7:871-7.

Wang Y, et al. The administration of Escherichia coli Nissle 1917 ameliorates irinotecan-induced intestinal barrier dysfunction and gut microbial dysbiosis in mice. Life Sci. 2019;231:116529.

Wang $Q$, et al. The differential distribution of bacteria between cancerous and noncancerous ovarian tissues in situ. J Ovarian Res. 2020;13:8.
Wardill HR, et al. Irinotecan-induced gastrointestinal dysfunction and pain are mediated by common TLR4-dependent mechanisms. Mol Cancer Ther. 2016;15:1376-86.

Wasserman $L$, et al. Sodium butyrate enhances the activities of membranal enzymes and increases drug sensitivity in a cell line from ascitic fluid of an ovarian carcinoma patient. Eur J Cancer Clin Oncol. 1989;25:1765-8.

Watanabe $\mathrm{M}$, et al. Bile acids induce energy expenditure by promoting intracellular thyroid hormone activation. Nature. 2006;439:484-9.

Wiegand KC, et al. ARID1A mutations in endometriosis-associated ovarian carcinomas. N Engl J Med. 2010;363:1532-43.

Wikoff WR, et al. Metabolomics analysis reveals large effects of gut microflora on mammalian blood metabolites. Proc Natl Acad Sci U S A. 2009;106:3698-703.

Wirtz HS, et al. Frequent antibiotic use and second breast cancer events. Cancer Epidemiol Biomarkers Prev. 2013;22:1588-99.

Woo BH, et al. Oral cancer cells sustainedly infected with Porphyromonas gingivalis exhibit resistance to Taxol and have higher metastatic potential. Oncotarget. 2017;8:46981-92.

Wortham BW, Patel CN, Oliveira MA. Polyamines in bacteria: pleiotropic effects yet specific mechanisms. Adv Exp Med Biol. 2007;603:106-15.

Xie X, Yang M, Ding Y, Chen J. Microbial infection, inflammation and epithelial ovarian cancer. Oncol Lett. 2017;14:1911-9.

Xu Y, Fang XJ, Casey G, Mills GB. Lysophospholipids activate ovarian and breast cancer cells. Biochem J. 1995:309(Pt 3):933-40.

Xu S, Liu Z, Lv M, Chen Y, Liu Y. Intestinal dysbiosis promotes epithelial-mesenchymal transition by activating tumor-associated macrophages in ovarian cancer. Pathog Dis. 2019;77(2):5420822.

Xu J, Peng JJ, Yang W, Fu K, Zhang Y. Vaginal microbiomes and ovarian cancer: a review. Am J Cancer Res. 2020;10:743-56.

Yabushita H, Sartorelli AC. Effects of sodium butyrate, dimethylsulfoxide and dibutyryl CAMP on the poorly differentiated ovarian adenocarcinoma cell line AMOC-2. Oncol Res. 1993;5:173-82.

Ye X. Lysophospholipid signaling in the function and pathology of the reproductive system. Hum Reprod Update. 2008;14:519-36.

Yokoyama MT, Carlson JR. Microbial metabolites of tryptophan in the intestinal tract with special reference to skatole. Am J Clin Nutr. 1979;32:173-8.

Yoneda J, et al. Expression of angiogenesis-related genes and progression of human ovarian carcinomas in nude mice. J Natl Cancer Inst. 1998;90:447-54.

Yoshimoto S, et al. Obesity-induced gut microbial metabolite promotes liver cancer through senescence secretome. Nature. 2013;499:97-101.

Yu LC. Microbiota dysbiosis and barrier dysfunction in inflammatory bowel disease and colorectal cancers: exploring a common ground hypothesis. J Biomed Sci. 2018;25:79.

Yuan M, et al. Repurposing the anticancer drug cisplatin with the aim of developing novel Pseudomonas aeruginosa infection control agents. Beilstein J Org Chem. 2018;14:3059-69.

Zabala D, Brana AF, Florez AB, Salas JA, Mendez C. Engineering precursor metabolite pools for increasing production of antitumor mithramycins in Streptomyces argillaceus. Metab Eng. 2013;20:187-97.

Zarrinpar A, Chaix A, Yooseph S, Panda S. Diet and feeding pattern affect the diurnal dynamics of the gut microbiome. Cell Metab. 2014;20:1006-17.

Zarrinpar A, Chaix A, Panda S. Daily eating patterns and their impact on health and disease. Trends Endocrinol Metab. 2016;27:69-83.

Zelante T, et al. Tryptophan catabolites from microbiota engage aryl hydrocarbon receptor and balance mucosal reactivity via interleukin-22. Immunity. 2013;39:372-85.

Zeng $L$, et al. Neoadjuvant chemotherapy for patients with advanced epithelial ovarian cancer: a meta-analysis. Sci Rep. 2016;6:35914.

Zerfaoui $\mathrm{M}$, et al. Poly(ADP-ribose) polymerase-1 is a determining factor in Crm1-mediated nuclear export and retention of p65 NF-kappa B upon TLR4 stimulation. J Immunol. 2010;185:1894-902.

Zhang Y-M, Rock CO. Membrane lipid homeostasis in bacteria. Nat Rev Microbiol. 2008:6:222-33.

Zhang M, Lee AH, Binns CW. Reproductive and dietary risk factors for epithelial ovarian cancer in China. Gynecol Oncol. 2004;92:320-6.

Zhang L, Zheng Y, Callahan B, Belfort M, Liu Y. Cisplatin inhibits protein splicing, suggesting inteins as therapeutic targets in mycobacteria. J Biol Chem. 2011;286:1277-82. 
Zhang B, et al. Effects of salinomycin on human ovarian cancer cell line OV2008 are associated with modulating p38 MAPK. Tumour Biol. 2012;33:1855-62.

Zhang T, et al. Discrimination between malignant and benign ovarian tumors by plasma metabolomic profiling using ultra performance liquid chromatography/mass spectrometry. Clin Chim Acta. 2012;413:861-8.

Zhang $\mathrm{T}$, et al. Identification of potential biomarkers for ovarian cancer by urinary metabolomic profiling. J Proteome Res. 2013;12:505-12.

Zhang L, Nichols RG, Patterson AD. The aryl hydrocarbon receptor as a moderator of host-microbiota communication. Curr Opin Toxicol. 2017;2:30-5.

Zhang H, Cherian R, Jin K. Systemic milieu and age-related deterioration. Geroscience. 2019;41:275-84.

Zhang $X$, et al. Dendritic cell vaccines in ovarian cancer. Front Immunol. 2020;11:613773.

Zheng L, Lin Y, Lu S, Zhang J, Bogdanov M. Biogenesis, transport and remodeling of lysophospholipids in Gram-negative bacteria. Biochim Biophys Acta Mol Cell Biol Lipids. 2017;1862:1404-13.
Zhou M, et al. Rapid mass spectrometric metabolic profiling of blood sera detects ovarian cancer with high accuracy. Cancer Epidemiol Biomarkers Prev. 2010;19:2262-71.

Zhou B, et al. The biodiversity composition of microbiome in ovarian carcinoma patients. Sci Rep. 2019a;9:1691.

Zhou B, et al. Clarithromycin synergizes with cisplatin to inhibit ovarian cancer growth in vitro and in vivo. J Ovarian Res. 2019b;12:107.

Zitvogel L, Ayyoub M, Routy B, Kroemer G. Microbiome and anticancer immunosurveillance. Cell. 2016:165:276-87.

Zitvogel L, Daillere R, Roberti MP, Routy B, Kroemer G. Anticancer effects of the microbiome and its products. Nat Rev Microbiol. 2017;15:465-78.

\section{Publisher's Note}

Springer Nature remains neutral with regard to jurisdictional claims in published maps and institutional affiliations.
Ready to submit your research? Choose BMC and benefit from:

- fast, convenient online submission

- thorough peer review by experienced researchers in your field

- rapid publication on acceptance

- support for research data, including large and complex data types

- gold Open Access which fosters wider collaboration and increased citations

- maximum visibility for your research: over $100 \mathrm{M}$ website views per year

At BMC, research is always in progress.

Learn more biomedcentral.com/submissions 